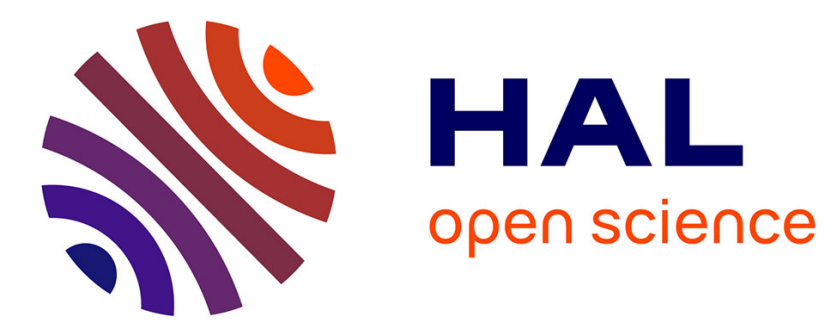

\title{
Output-based allocations in pollution markets with uncertainty and self-selection
}

\author{
Guy Meunier, Juan-Pablo Montero, Jean-Pierre Ponssard
}

\section{To cite this version:}

Guy Meunier, Juan-Pablo Montero, Jean-Pierre Ponssard. Output-based allocations in pollution markets with uncertainty and self-selection. 2016. hal-01321372

\section{HAL Id: hal-01321372 \\ https://hal.science/hal-01321372}

Preprint submitted on 25 May 2016

HAL is a multi-disciplinary open access archive for the deposit and dissemination of scientific research documents, whether they are published or not. The documents may come from teaching and research institutions in France or abroad, or from public or private research centers.
L'archive ouverte pluridisciplinaire HAL, est destinée au dépôt et à la diffusion de documents scientifiques de niveau recherche, publiés ou non, émanant des établissements d'enseignement et de recherche français ou étrangers, des laboratoires publics ou privés. 


\title{
ECOLE POLYTECHNIQUE
}

\section{Output-based allocations in pollution markets with uncertainty and self-selection}

\author{
GuY MEUNIER \\ Juan-Pablo MONTERO \\ Jean-Pierre PONSSARD
}

May 6, 2016

Cahier $n^{\circ}$ 2016-05

\section{DEPARTEMENT D'ECONOMIE}

Route de Saclay

91128 PALAISEAU CEDEX

(33) 169333033

http://www.economie.polytechnique.edu/

mariame.seydi@polytechnique.edu 


\title{
Output-based allocations in pollution markets with uncertainty and self-selection
}

\author{
Guy Meunier, Juan-Pablo Montero and Jean-Pierre Ponssard* \\ May 6, 2016
}

\begin{abstract}
We study pollution permit markets in which a fraction of permits are allocated to firms based on their output. Output-based allocations, which are receiving increasing attention in the design of carbon markets around the world (e.g., Europe, California, New Zealand), are shown to be optimal under demand and supply volatility despite the output distortions they may create. In a market that covers multiple sectors, the optimal design combines auctioned permits with output-based allocations that are specific to each sector and increasing in its volatility. When firms are better informed about the latter or must self select, the regulator resort to some free (i.e., lump-sum) allocations to sort firms out. Numerical exercises illustrate the policy relevance of our results: the gains from considering output-based allocations can be substantial.
\end{abstract}

JEL Classification: D24, L13, H23, L74

Keywords: pollution markets, output-based allocations, market volatility, selfselection, climate policy

\section{Introduction}

In the last 25 years we have seen a dramatic increase in the use of permit markets to control pollution 1 In all of them the allocation of permits has been a critical issue. In some markets permits are allocated for free according to historic emissions, while in others they are auctioned off, at least a fraction of them. The carbon market in Europe, for example, is moving away from free allocations in favor of auctions ${ }^{2}$ Another issue, which is the focus

*Meunier (guy.meunier@ivry.inra.fr): INRA-UR1303 ALISS and Department of Economics, Ecole Polytechnique. Montero (jmontero@uc.cl): Department of Economics and Center for Global Change, PUC-Chile. Ponssard (jean-pierre.ponssard@polytechnique.edu): Department of Economics, Ecole Polytechnique. We thank Carolyn Fischer, Natalia Fabra and seminar participants at the 2015 EAERE Meeting in Helsinki, the 2015 PET conference in Luxembourg, and the 2016 Workshop on Developments in Energy Economics in Madrid for comments. Meunier and Ponssard also thank the financial support of the chair Energy and Prosperity, the Ecole Polytechnique - EDF chair for Sustainable Development, and ANR/Investissements d'avenir (ANR -11- IDEX-0003-02), and Montero of Fondecyt (Grant No. 1130998).

${ }^{1}$ See Kossoy et al. (2015) and Newell et al. (2013) for an overview of existing carbon markets around the world.

${ }^{2}$ http://ec.europa.eu/clima/policies/ets/cap/allocation/index_en.htm 
of this article, is whether the total number of permits to be allocated should be fixed from the start, as in the sulfur market in the US (Schmalensee et al., 1998), or vary according to market conditions. The carbon market in California, for example, considers a price floor and ceiling to which the total number of permits must adjust for the permit price to move within that range (Borenstein et al. 2015).

Since the seminal work of Weitzman (1974) much has been written on the design of permit markets subject to demand and supply shocks. Weitzman (1974) anticipated that any regulatory design, whether is based on prices or quantities, is subject to errors in the presence of market fluctuations, so the policy design challenge is to keep those errors at a minimum. Roberts and Spence (1976) were the first to respond to the challenge with a hybrid permit scheme in which the regulator is ready to issue extra permits if the price hits a pre-determined ceiling and buy back permits if it reaches a floor ${ }^{3}$ Letting firms to move permits intertemporally has also been proposed (Rubin, 1996) and used in different markets (e.g. Ellerman and Montero, 2007) as a way to smooth market shocks. More recently, Newell and Pizer (2008) and Branger and Quirion (2014) propose to index the allocation of permits to any exogenous variable, such as GDP, that could be correlated to shocks affecting permit prices. And in the specific context of the carbon market in the EU, there are proposals to introduce a market stability reserve from or to which auctioned permits could be withdrawn or add as the number of unused (i.e., banked) permits in the market reaches a critical level that could push permit prices either too high or too low (Kollenberg and Taschini, 2015).

In this article we are also interested in ways in which permit markets can accommodate to market fluctuations. We are particularly interested in market schemes in which a fraction of the permits are allocated to firms based on their output while the remaining fraction is allocated through either auctioning or grandfathering. Output-based allocation (OBA) schemes have been introduced and considered in a number of existing and proposed permit markets, most notably, the carbon markets in California, the EU and New Zealand. ${ }^{4}$ Because OBA schemes have the ability to directly affect firms' output decisions, they have received considerable attention to deal with leakage problems. By preventing firms not affected by the permits market to increase their output and, hence, their emissions relative to affected firms, OBA schemes has been proposed as an alternative, albeit inferior, to border tax adjustments (Fischer and Fox, 2007; Quirion, 2009; Monjon and Quirion, 2011; Fischer and Fox, 2012; Meunier et al., 2014). $\left.\right|^{5}$ They have also been proposed to deal with market power problems (Fischer, 2011; Fowlie et al., 2016).

In this article we abstract from leakage and market power issues and focus exclusively on the performance of OBA schemes under uncertainty, a problem that has received much less attention in the literature, if at all 6 One possible explanation for this lack of attention is

\footnotetext{
$\sqrt[3]{\text { Berglann }}(2012)$ also proposes a hybrid scheme in which firms trade pollution-permit shares and pay taxes depending on their emissions and number of shares they hold.

${ }^{4}$ In Sweden, a refunded emission payments program based on firms' output was introduced in 1992 to control NOx emissions. It was made output-based to facilitate the industry acceptance to the regulation (for an evaluation of this scheme see Sterner and Isaksson, 2006).

${ }^{5}$ For example, Burtraw et al. (2015) suggested that OBA should be considered to mitigate leakage within the US since the implementation of the Clean Power Plan may lead to state-specific regulations.

${ }^{6}$ The only article that study OBA schemes under uncertainty is Meunier et al. (2014), but again the focus is on leakage not on the implication of having a flexible permit allocation. Nevertheless, in the numerical section of the article we run an exercise where leakage is also present. Our numbers indicate that
} 
that in the absence of leakage and/or market power there is no reason to subsidy production, which is what OBA schemes ultimately do. In the presence of uncertainty, however, these subsidies play an additional role, which is to let the total number of permits to adjust to demand and supply shocks. For instance, if there is a positive demand shock, firms will respond with more output and a higher demand for permits. If the total number of permits is fixed, this higher demand will translate in an inefficiently high permit price (i.e., above the marginal harm from pollution); unless the total number of permits is increased, which is what an OBA scheme would endogenously do.

Any OBA scheme still presents the regulator with a trade-off because the adjustment in the number of permits comes at the cost of distorting production away from the socially optimal level. This trade-off raises several questions that we tackle in different sections of the article. We start in Section 2 by asking whether an OBA scheme would ever be optimal for an industrial sector with a large number of firms. We establish that an OBA scheme should be considered whenever we observe a positive covariance between permit prices and output under a fixed permit allocation (Proposition 1). This is true even if the market design already considers a price stability mechanism such as price thresholds at which the regulator is ready to either sell or buy back permits to stabilize prices (following Roberts and Spence, 1976, and the California market). Whenever these price thresholds are optimally set, we establish (for linear demand and marginal costs) that introducing OBAs is indeed optimal (Proposition 2).

To understand why an OBA scheme can be welfare enhancing, suppose the regulator issues a fixed number of permits such that the expected permit price is equal to the marginal harm from pollution. If in addition, the regulator issues a few permits based on firms' output, these few OBA permits will lead to both more output (the subsidy effect) and more emissions relative to the fixed allocation. The increase in output is clearly inefficient but becomes of second order as the fraction of OBA permits goes to zero. Conversely, the increase in emissions can be a good or bad depending on whether the demand/supply shocks are positive or negative. Since the marginal increase in emissions is exactly equal to output as the OBA rate goes to zero $]^{7}$ if the correlation between output and permit prices is positive the increase in emissions will be larger when the permit price is above the marginal harm than when it is below, which results in a net welfare gain.

This positive result is only reinforced as we introduce several sectors. Because firms covered by a permit market are never identical, as they belong to different productive sectors or regions, in Section 3 we look at the optimal OBA design when there are multiple sectors subject to different shocks. Sector heterogeneity introduces a covariance between permit prices and sector output - which vary from sector to sector in magnitude and sometimes direction - making OBA always worth implementing. The optimal OBA scheme has, in addition to a fraction of auctioned permits, sectors subject to bigger shocks receiving higher OBA rates (Propositions 3 and 4).

One potential implementation problem with this multi-sector OBA scheme is that it discriminates across sectors creating perverse incentives for sectors to pretend they face

demand/supply uncertainty can be far more important a factor for the use OBAs than leakage is.

${ }^{7}$ Recall that we are assuming perfect compliance, so total emissions are equal to some fixed amount of permits (which can be auctioned off or grandfathered) plus the OBA rate times output. 
bigger shocks than they actually do or to simply lobby for larger OBA rates ${ }^{8}$ So, even if the regulator knows sectors well, it may be unfeasible for her to sort them out without relying on self selection. Fortunately, there is a simple way for the regulator to go around this selection problem while preserving the optimal OBA outcome: to use a fraction of the auctioned permits to construct menus of OBA rates and free (i.e., lump-sum) permits (Proposition 5). Sectors facing smaller shocks are ready to take lower OBA rates because they are compensated with a larger fraction of lump-sum permits. The "single-crossing property" that allows for this separation of sectors is that more volatile sectors are willing to pay more for a marginal increase in the OBA rate.

Motivated by discussions on how to reform carbon markets around the world and in Europe in particular $9^{9}$ in Section 4 we use our model to revisit several critical issues in the design of these markets. In particular, we look at how different OBA schemes manage permit price fluctuations and what are the implications of deducting OBA permits (the majority going to trade-exposed and carbon intensive sectors) from the overall permit allocation so as to keep the global cap on emissions fixed (as it is the case in California and is contemplated in the EU). Our numerical results show that an OBA scheme can significantly reduce carbon price fluctuation as long as its implementation considers a flexible cap on total emissions. Insisting on a fixed cap would only increase price fluctuations and induce severe welfare losses on non-OBA sectors (mainly electricity). Furthermore, the introduction of OBA permits together with a flexible global cap generate almost no distortion in these non-OBA sectors. Our results also indicate that self selection (i.e., lobbying for more OBA rates) is much less of problem, if at all; all simulations show that there are enough auctioned permits to cope with it. All these results indicate that supply and demand shocks make a strong case for the use of OBAs, even more than leakage does. In any case, these preliminary results derived from our simple framework are quite illuminating for policy analysis and should deserve further work.

The rest of the article is organized as follows. We start in the next section with a permit market that covers a single-sector with a large number of firms to demonstrate that the optimality of OBA schemes holds quite generally. In Section 3 we extend the analysis to cover multiple sectors, each of which facing independent shocks. Section 4 contains the numerical exercises illustrating that the gains from using OBA schemes can be substantial, but only if properly designed. We conclude in Section 5.

\section{A single-sector model}

Consider a competitive market for an homogeneous good subject to demand and supply shocks. Inverse demand is given by $P(q ; \theta)$ where $q$ is total consumption and $\theta \in\left[\theta_{\min }, \theta_{\max }\right]$ is a demand shock. Function $P(\cdot)$ is positive, differentiable and decreasing in $q$ and increasing

\footnotetext{
${ }^{8}$ This asymmetric information problem is different from the problems of asymmetric information and pollution control we find in the literature (e.g. Dasgupta et al., 1980, Spulber, 1988; Lewis, 1996, Montero, 2008). One reason is that the full-information OBA scheme is not first best; another is that the sorting condition required to separate sectors is endogenous to the regulatory design.

${ }^{9}$ See for instance the articles discussed at the workshop "Markets for CO2: comparing the Californian and European Experiences", Nov 13-14 2014, Paris. The program and the working articles presented at the workshop are available at http://www.cdcclimat.com/Workshop-Markets-for-CO2-Permits.html
} 
in $\theta$. The corresponding consumer gross surplus is $S(q ; \theta)$ with $S_{q}=P(q ; \theta)$. 10 The good is supplied by an industrial sector with a large number of price-taking firms. The sector's cost of producing $q$ while polluting $e$ is $C(q, e ; \eta)$, where $\eta \in\left[\eta_{\min }, \eta_{\max }\right]$ is a supply shock. Function $C(\cdot)$ is positive and increasing in $q$ and $\eta$, decreasing in $e$ and

$$
C_{q e}<0, C_{q q}>0, C_{e e}>0 \text { and } C_{q q} C_{e e}>C_{q e}^{2} .
$$

This formulation assumes that output and pollution are cost complements (see Spulber. 1988; Lewis, 1996).

Damage from pollution depends on total emissions according to $D(e)$, a positive, increasing and convex function. For any given realization of $\theta$ and $\eta$, social welfare is computed as the difference between gross consumer surplus, production costs and pollution damage

$$
W(q, e, \theta, \eta)=S(q ; \theta)-C(q, e ; \eta)-D(e)
$$

so expected welfare is denoted by

$$
\tilde{W}=\mathbb{E}_{\theta, \eta}[S(q(\cdot) ; \theta)-C(q(\cdot), e(\cdot) ; \eta)-D(e(\cdot))]
$$

Throughout, we assume that shocks $\theta$ and $\eta$ move within a range that there is positive production and pollution abatement in equilibrium for all states of demand and supply and regulatory designs (including no intervention).

\subsection{OBA regulation and market equilibrium}

In the absence of government intervention, the market equilibrium $P(q ; \theta)=C_{q}(q, e ; \eta)$ and $C_{e}(q, e ; \eta)=0$ leads to too much pollution. To correct for this, the regulator implements a permit market where the total amount of permits may not be fixed but endogenous to output. The regulator auctions off $\bar{e}$ permits and in addition allocates permits to firms based on their output ${ }^{11}$ For each unit of output, a firm gets $\alpha$ permits for free, so the total amount of pollution/permits in any given period is equal to

$$
e=\bar{e}+\alpha q
$$

In what follows, we will refer to $\alpha$ as the OBA rate. Most of the article is about to understand the conditions under which it is socially optimal to set $\alpha>0$, whether there is a single sector like here or multiple sectors like in the next section.

At the beginning of each period firms learn $\theta$ and $\eta$, after which they decide how much to produce and pollute anticipating the additional permits they will get for their output. Since the permit market is perfectly competitive, the auction clears at the price firms expect to trade permits in the secondary market. We denote this price by $r$. Thus, each firm takes $r$

\footnotetext{
${ }^{10}$ Partial derivatives are sometimes denoted by a subscript, e.g., $S_{q} \equiv \partial S / \partial q$.

${ }^{11}$ In principle, the $\bar{e}$ permits could also be allocated for free to firms based, for example, on historic emissions. But as soon as we allow for some positive cost of public funds (Goulder et al., 1997), auctioning becomes optimal. Our implicit assumption in the article is that the cost of public funds is positive but arbitrarily small, so we do not need to explicitly model it.
} 
and the output price $p=P(q ; \theta)$ as given and solve (think of $C(\cdot)$ as the cost function of a representative firm)

$$
\max _{q, e} p q-C(q, e ; \eta)-r(e-\alpha q)
$$

leading to the first-order equilibrium conditions

$$
p=C_{q}(q, e ; \eta)-\alpha r
$$

and

$$
r=-C_{e}(q, e ; \eta)
$$

Equilibrium prices $p$ and $r$ are in turn obtained using (4).

Since OBA is a subsidy to production, the first-order conditions are standard ones. A firm will produce to the point where the marginal cost of production is equal to the output price plus the OBA subsidy. Similarly, the firm will abate emissions to the point where the marginal cost of doing so is equal to the permit price.

Details on how the equilibrium levels of production $q$ and pollution $e$ respond to shocks $\theta$ and $\eta$ and the regulatory variables $\bar{e}$ and $\alpha$ are in Appendix A.1. One aspect worth commenting here is the non-monotonic influence of the OBA rate $\alpha$. From looking at the first-order conditions (5) and (6), one could decompose the effect of an increase in $r$ on $q$ in two opposing effects: a positive effect due to the increase in the OBA subsidy and a negative effect due to more pollution abatement 12 When $\alpha$ is small, the second effect dominates, so an increase in $r$ would lead to a drop in $q$. Conversely, when $\alpha$ is large, the first effect may dominate, and an increase in $r$ may well lead to an increase in $q$ as well. For these same reasons, the effect of a marginal increase in $\alpha$ or in $\bar{e}$ on output and pollution cannot be signed a priori when $\alpha$ is large. Fortunately, there is no need to delve much into these monotonicity issues. For most part we only need to focus on the welfare effects of a small $\alpha$, for which the monotonicity is clear, and when we take the model to a linear world, as done in the next two sections, the monotonicity is preserved even for large $\alpha$.

\subsection{Optimal OBA scheme}

We now turn to the optimal permit design and to see whether setting $\alpha>0$ is ever optimal. Before doing so, it helps to ask what would be the optimal number of permits $\bar{e}$ if we set $\alpha=0$.

Lemma 1 When the $O B A$ rate is set equal to zero (i.e., $\alpha=0$ ), the optimal number of permits to be auctioned off, $\bar{e}$, is such that the expected permit price is equal to the marginal environmental damage.

Proof. If $\alpha=0$, the quantity of emissions is $\bar{e}$ in all demand states, hence, by the envelope theorem, we have that

$$
\tilde{W}_{\bar{e}}(\bar{e}, \alpha=0)=\mathbb{E}\left[-C_{e}-D^{\prime}(\bar{e})\right]=\mathbb{E}[r]-D^{\prime}(\bar{e})
$$

\footnotetext{
${ }^{12}$ As done in the Appendix A.1, totally differentiating (5) and (6) with respect to $r$ yields $d q / d r=$ $\left[C_{q e}+\alpha C_{e e}\right] / \delta_{1}$ and $d e / d r=-\left[C_{q q}-P_{q}+\alpha C_{q e}\right] / \delta_{1}$, where $\delta_{1}=C_{q q} C_{e e}-P_{q} C_{e e}-C_{q e}^{2}>0$.
} 
so, at the optimum $\mathbb{E}[r]=D^{\prime}(\bar{e})$.

By letting the permit price fluctuate around the marginal harm $D^{\prime}(\bar{e})$, the authority minimizes the errors from a policy that never hits the first-best ex-post, except when the shocks $\theta$ and $\eta$ are such that $r(\theta, \eta)=D^{\prime}(\bar{e})$. The question now is whether setting a positive OBA rate, $\alpha>0$, helps minimize those errors any further. Maintaining the auction allocation fixed at $\bar{e}$, the welfare effect of adding a few OBA permits to the market is

$$
\tilde{W}_{\alpha}(\bar{e}, \alpha)=\mathbb{E}\left[-\alpha r q_{\alpha}+\left(r-D^{\prime}(e)\right) e_{\alpha}\right]
$$

The first term captures the welfare loss from the output distortion introduced by the OBA subsidy (notice from Appendix A.1 that both $q_{\alpha}$ and $e_{\alpha}$ are positive when $\alpha$ is not too large, which is the relevant case for the next proposition). As captured by the second term, however, this loss can be potentially compensated by a gain from higher emissions whenever the permit price $r$ is above $D^{\prime}(\bar{e})$. But since $\mathbb{E}[r]=D^{\prime}(\bar{e})$, it is not evident that the gains from allocating additional permits in periods when $r>D^{\prime}(\bar{e})$ are not exactly offset by the losses from increasing emissions in periods when $r<D^{\prime}(\bar{e})$. In fact, in a world of certainty, when $\bar{e}$ is such that $r=D^{\prime}(\bar{e})$, setting $\alpha>0$ only reduces welfare because you are left with just the first term.

In a world of changing supply and demand this logic may not apply, as the next proposition shows.

Proposition 1 Consider a permit market with $\alpha=0$ and $\bar{e}^{0}$ such that $D^{\prime}\left(\bar{e}^{0}\right)=\mathbb{E}[r]$. If in that market we observe a positive correlation between permit prices and output, then it is optimal to introduce a positive OBA rate, $\alpha>0$. Furthermore, the optimal OBA scheme $(\bar{e}, \alpha)$ in that case satisfies the system of equations

$$
\begin{aligned}
\mathbb{E}\left[r-D^{\prime}(e)\right] & =\alpha \mathbb{E}\left[D^{\prime}(e) q_{\bar{e}}\right] \\
\operatorname{cov}\left(\frac{\partial W}{\partial \bar{e}}, q\right) & =\alpha \mathbb{E}\left[D^{\prime}(e) \frac{-C_{e}}{\delta_{2}}\right]
\end{aligned}
$$

where $\delta_{2}=-P_{q}+C_{q q}+2 \alpha C_{q e}+\alpha^{2} C_{e e}>0$.

Proof. Notice first that $\delta_{2}>0$ thanks to assumption (1). Now, from Lemma 1 notice that when $\alpha=0$, it is optimal to set $\bar{e}^{0}$ such that $\mathbb{E}[r]=\bar{D}^{\prime}\left(\bar{e}^{0}\right)$. Next, from equation (4) obtain $e_{\alpha}=q+\alpha q_{\alpha}$, which replaced into (7) together with $\alpha=0$ yields

$$
\tilde{W}_{\alpha}\left(\bar{e}^{0}, \alpha=0\right)=\mathbb{E}\left[\left(r-D^{\prime}\left(\bar{e}^{0}\right)\right) q\right]
$$

Since $D^{\prime}\left(\bar{e}^{0}\right)$ is constant and equal to the expected permit price, $\tilde{W}_{\alpha}\left(\bar{e}^{0}, \alpha=0\right)$ is positive if

$$
\mathbb{E}\left[\left(r-D^{\prime}\left(\bar{e}^{0}\right)\right) q\right]=\mathbb{E}\left[r-D^{\prime}\left(\bar{e}^{0}\right)\right] \mathbb{E}[q]+\operatorname{cov}(r, q)=\operatorname{cov}(r, q)>0
$$

The system (8) and (9), on the other hand, is obtained by simply rearranging the optimality conditions

$$
\tilde{W}_{\bar{e}}(\bar{e}, \alpha)=\mathbb{E}\left[-\alpha r q_{\bar{e}}+\left(r-D^{\prime}(e)\right) e_{\bar{e}}\right]=0
$$

and $\tilde{W}_{\alpha}(\bar{e}, \alpha)=0$, where $\tilde{W}_{\alpha}(\bar{e}, \alpha)$ is given by (7). To arrive at (8), obtain first $e_{\bar{e}}=1+\alpha q_{\bar{e}}$ from (4) and then plug it into (12). 
To arrive at (9), obtain first $e_{\alpha}=q+\alpha q_{\alpha}$ from (4) and plug it into (7) to obtain

$$
\tilde{W}_{\alpha}(\bar{e}, \alpha)=\mathbb{E}\left[\left(r-D^{\prime}(e)\right) q-\alpha D^{\prime}(e) q_{\alpha}\right]=0
$$

Now, replacing $q_{\alpha}=q q_{\bar{e}}-C_{e} / \delta_{2}$, which is derived in Appendix A.1 (see equation (42)), in (13) yields

$$
\tilde{W}_{\alpha}(\bar{e}, \alpha)=\mathbb{E}\left[\left\{r-D^{\prime}(e)-\alpha D^{\prime}(e) q_{\bar{e}}\right\} q+\alpha D^{\prime}(e) C_{e} / \delta_{2}\right]=0
$$

But the term in curly brackets is $\partial W / \partial \bar{e}$, which can be seen directly from (8), so using $\mathbb{E}[\{\partial W / \partial \bar{e}\} q]=\operatorname{cov}(\partial W / \partial \bar{e}, q)$ we finally arrive at $(9)$.

Production is inefficiently high with OBA given the number of emissions, however, with uncertainty this inefficiency might be worth the flexibility in the cap created by OBA. Whether it is the case can be easily checked by looking at the covariance between the permit price and the quantity produced. A positive OBA rate relaxes the overall emissions cap in all demand and supply states, which has a positive (resp. negative) welfare effect in "high" (resp. low) states of demand/supply, that is, in states in which the permit price is higher (resp. lower) than the marginal environmental damage. Therefore, the net welfare effect depends one whether the gains in high demand/supply states more than offset the losses in low demand/supply states. When the OBA rate is small, the gain (or loss) in each state is equal to the difference between the permit price and the marginal environmental damage times the number of extra permits. But this latter is exactly equal to output when $\alpha=0$, so if output tend to be larger in periods when permit prices are high and above marginal damages, then, the net welfare effect from injecting a few extra permits in all states must be positive.

The exact choice of the regulatory variables $\alpha$ and $\bar{e}$, captured by equations (8) and (9), are the result of the trade-off the regulator must solve between output distortion and additional emissions. Because a marginal increase in $\alpha$ or $\bar{e}$ results in more emissions and output, the exact same trade-off is present in both (7) and (12). In (7), and given some $\bar{e}$, the regulator will increase $\alpha$ to the point in which the additional (expected) loss from the output distortion $\left(-\alpha r q_{\alpha}\right)$ is exactly equal to the extra gain from having relatively more emissions in periods of higher permit prices. Likewise, in (12), and given $\alpha>0$, the regulator will increase $\bar{e}$ to the point in which the additional (expected) loss from the output distortion $\left(-\alpha r q_{\bar{e}}\right)$ is exactly equal to the extra gain from having more emissions in periods of higher permit prices. Notice from (8) that $\bar{e}$ is set below the level that equalizes marginal damages $D^{\prime}(e)$ to expected prices $\mathbb{E}[r]$. This is done to correct for the additional permits that are brought to the market in each period by setting $\alpha>0$.

Proposition 1 says that observing permit prices and output to fluctuate overtime is not enough to implement an OBA scheme. The latter requires output to be positively correlated with permit prices, which ultimately depends on the impact of shocks $\theta$ and $\eta$ on prices and cost functions. So, the relevant question is how likely is to observe a positive correlation. We argue that it is most likely (perhaps the best example is the carbon market in Europe where the positive correlation has been reinforced by the sharp drop in permit prices during the recent international crisis). For instance, if demand is the main source of uncertainty, when demand is high both permit prices and output will be high. Similarly, if shocks affect primarily production costs (e.g., the oil price), when production costs are high both output and permit prices will be low. We cannot rule out in theory, however, cases that may exhibit 
a negative correlation. For example, if abatement cost are the main source of uncertainty, high abatement costs could lead to both high permit prices and low output. These examples are summarized in the following lemma.

Lemma 2 A small positive $O B A$ rate increases welfare (i.e., $\tilde{W}_{\alpha}(\alpha=0)>0$ ) when, for example, (i) $P_{\theta}>0$ and $C_{\eta}=0$, or (ii) $P_{\theta}=0, C_{q \eta}>0$ and $C_{e \eta}>0$. Conversely, $a$ small positive $O B A$ rate may decrease welfare if the permit price does not vary with $\theta$ and the marginal abatement cost $-C_{e}$ increases sufficiently more than the marginal production cost $C_{q}$ with respect to $\eta$ (i.e., $P_{\theta}=0, C_{q \eta}>0$ and $-C_{e \eta}>-C_{q e} C_{q \eta} /\left(C_{q q}-P_{q}\right)$ ).

\section{Proof. See Appendix A.2.}

Because the implementation of an OBA scheme not only requires the regulator issuing additional permits each period but also setting different OBA rates to different groups of firms (a topic covered in Sections 3.1 and 3.2), one may argue that the gains from implementing an OBA scheme may not be sufficient to justify its implementation costs. Our numerical exercises of Section 4 show otherwise, that the gains from implementing OBA can be substantial. And having different groups of firms does not make the implementation of OBA much more difficult; it may require the regulator to allocate a fraction of the auctioned permits in a lump-sum manner to sort firms out into the scheme (this is covered in Section 3.3). Yet, some may argue that OBA permits may not be necessary if the regulator opts for an alternative (flexible) allocation scheme. The next section points otherwise.

\subsection{Hybrid design}

An OBA scheme is one of several ways to let the overall emissions cap to adjust to demand and supply shocks. Alternatives include the introduction of a market stability reserve (which is closely related to banking and borrowing provisions) or the use of a hybrid permit scheme with a price floor and ceiling as first proposed by Roberts and Spence (1976) and recently adopted in California (Borenstein et al. 2015). Since an optimal hybrid scheme is strictly superior to the best market stability reserve (or best banking and borrowing provisions for that matter) ${ }^{13}$ in this section we study whether the introduction of an OBA scheme still plays a role in a well designed hybrid permit market.

Consider then a hybrid design with a price ceiling and price floor, which we denote, respectively, by $\bar{r}$ and $\underline{r}$. These thresholds are equivalent to setting a penalty for not compliance equal to $\bar{r}$ and a subsidy for over-compliance equal to $\underline{r}$. The regulatory timing is as before: price thresholds $\bar{r}$ and $\underline{r}$ are set ex-ante together with the number of auctioned permits $\bar{e}$ and the OBA rate $\alpha$.

To simplify the presentation we will only consider demand shocks $\theta$, which are assumed to be drawn from the cumulative distribution function $F(\theta)$. If the demand for permits is sufficiently high (resp. low), the price of permits will be equal to $\bar{r}$ (resp. $\underline{r}$ ). Since the demand for permits is increasing with respect to the demand state $\theta$ (see Appendix A.1), there will be two demand states $\underline{\theta}$ and $\bar{\theta}>\underline{\theta}$ such that: (i) when $\theta \in\left[\theta_{\min }, \underline{\theta}\right], r=\underline{r}$ and

\footnotetext{
${ }^{13}$ Unlike Roberts and Spence $(1976)$, banking and borrowing work through firms' intertemporal optimization paying little attention to environmental damages. Introducing exchange rates to alter how firms borrow or save permits does not work either.
} 
$e-\alpha q \leq \bar{e}$; (ii) when $\theta \in(\underline{\theta}, \bar{\theta}), \underline{r}<r<\bar{r}$ and $e-\alpha q=\bar{e}$; and (iii) when $\theta \in\left[\bar{\theta}, \theta_{\max }\right], r=\bar{r}$ and $e-\alpha q \geq \bar{e}$.

Notice that in this hybrid scheme there will be not one but three instances in which the policy will be ex-post efficient. One is for a low demand shock $\theta \in\left(\theta_{\min }, \underline{\theta}\right)$ such that $\underline{r}=D^{\prime}(e(\theta)-\alpha q(\theta)<\bar{e})$; the second for an intermediate demand shock $\theta \in(\underline{\theta}, \bar{\theta})$ such that $r=D^{\prime}(\bar{e})$; and the third for a high demand shock $\theta \in\left(\bar{\theta}, \theta_{\max }\right)$ such that $\bar{r}=$ $D^{\prime}(e(\theta)-\alpha q(\theta)>\bar{e})$.

When $\alpha=0$, the optimal hybrid design $(\bar{e}, \underline{r}, \bar{r})$ solves the following system of equations

$$
\begin{aligned}
& \tilde{W}_{\bar{e}}=\int_{\underline{\theta}}^{\bar{\theta}}\left[r(\theta)-D^{\prime}(\bar{e})\right] d F(\theta)=0 \\
& \tilde{W}_{\underline{r}}=\int_{\theta_{\min }}^{\underline{\theta}}\left[\underline{r}-D^{\prime}(e(\theta))\right] e_{\underline{r}} d F(\theta)=0 \\
& \tilde{W}_{\bar{r}}=\int_{\bar{\theta}}^{\theta_{\max }}\left[\bar{r}-D^{\prime}(e(\theta))\right] e_{\bar{r}} d F(\theta)=0
\end{aligned}
$$

Equation (14) follows the same logic of the previous section. In the demand range where emissions are fixed at $\bar{e}$ and the permit price varies with $\theta$, it is optimal to have the expected permit price be equal to the marginal damage. In the other two regions, however, where prices are fixed but emissions adjust to shocks, equations (15) and (16) show that what is optimal is to have the fixed price be equal to expected marginal damages (weighted by either $e_{\underline{r}}$ or $e_{\bar{r}}$, unless they are invariant to $\theta$ ).

Introducing both a price floor and ceiling allows the equilibrium permit price to follow more closely the marginal environmental damage for different realizations of $\theta$ (cf. Roberts and Spence, 1976). Whether it is worth adding some OBA permits over this more flexible design is not obvious because extreme permit price realizations have now been truncated, which also has an effect on output outcomes. To check the optimality of OBA we proceed as before by considering the welfare effect of introducing an arbitrarily small OBA rate over this optimal hybrid scheme. Changes in expected welfare at $\alpha=0$ are only due to changes in emissions because there is no production inefficiency when $\alpha=0$; hence, $W_{\alpha}=\mathbb{E}\left[\left(r-D^{\prime}\right) e_{\alpha}\right]$.

Since $e_{\alpha}=q$ in the demand range where emissions are fixed at $\bar{e}$, this welfare change can be decomposed as

$$
\begin{aligned}
\tilde{W}_{\alpha}(\alpha= & 0)=\int_{\theta_{\min }}^{\underline{\theta}}\left(\underline{r}-D^{\prime}(\theta)\right) e_{\alpha} d F \\
& +\int_{\underline{\theta}}^{\bar{\theta}}\left(r-D^{\prime}(\bar{e})\right) q d F+\int_{\bar{\theta}}^{\theta_{\max }}\left(\bar{r}-D^{\prime}(\theta)\right) e_{\alpha} d F
\end{aligned}
$$

The OBA rate has a different influence in intermediary demand states than in the more extreme ones. In intermediary states, there is both a direct effect on emissions due to the increased number of free permits and an indirect effect via the rise of production due to a higher subsidy. In extreme demand states, the permit price is fixed, and free allocations alleviate the bill of the firm but not its emission choice. However, there is still the subsidy channel that induces higher emissions due to higher production. The influence of the OBA 
rate is positive for intermediary demand states (second term above). The magnitude of this positive effect depends on how often $\theta \in[\underline{\theta}, \bar{\theta}]$ and the covariance between output and permit prices. The first and third term are more difficult to sign because of the influence of $\alpha$ on emissions when the floor or ceiling bind, and how this influence compares to the influence of the permit price on emissions.

Proposition 2 Suppose we observe a positive correlation between permit prices and output in the optimal hybrid design with $\alpha=0$. If the influence of the OBA rate and of the price floor and ceiling on emissions do not vary with demand (i.e., $e_{\alpha \theta}=e_{\bar{r} \theta}=e_{\underline{r} \theta}=0$ ), then a strictly positive $O B A$ rate increases welfare (This is so when demand is linear, uncertainty is additive and cost is quadratic).

Proof. When $e_{\bar{r}}$ and $e_{\alpha}$ are independent of the demand shock $\theta$, the optimal price floor solves

$$
\underline{r}=\mathbb{E}\left[D^{\prime}(e(\theta)) \mid \theta<\underline{\theta}\right]
$$

so the first term in (17) is zero. Since the same applies to the third term, the welfare effect of adding a few OBA permits will be positive if the second term is positive, which requires of a positive correlation between permit prices and output.

Propositions 1 and 2 show that an OBA scheme is likely to be beneficial in the context of a single sector, even if there is a flexible scheme already in place. We now explains how this result extends to multiple sectors, which is the more realistic case.

\section{$3 \quad$ Multiple sectors}

The single-sector analysis provides us with the solution to the OBA problem when the regulator sets the same rate $\alpha$ to all firms, whatever similar or different they might be. In reality firms covered by a permits market are never identical for different reasons. They may use different production technologies, belong to different productive sectors or simply be located in different regions. In this section we look at the optimal OBA design when there are multiple sectors subject to different shocks (or when the regulator can assign firms to different groups). To make the problem even more interesting we adopt the extreme assumption that the only abatement technology available is output reduction (we do not want to leave the impression that abatement is essential to generate a correlation between permit prices and output). We start with a general set-up and then introduce some simplifying assumptions to derive additional results.

\subsection{General set-up}

Consider a permit market covering a large number $n$ of sectors, each of which takes the price of permits as given. In each sector there is a continuum of identical firms. Production in sector $i=1, \ldots, n$ is denoted by $q_{i}$ and since the only abatement technology is output reduction, we normalize emissions to output, i.e., $e_{i}=q_{i}$. As in the previous section, inverse demand in sector $i$ is denoted by $P_{i}\left(q_{i}, \theta_{i}\right)$, consumer surplus by $S_{i}\left(q_{i} ; \theta_{i}\right)=\int_{0}^{q_{i}} P_{i}\left(x ; \theta_{i}\right) d x$, 
and production costs by $C_{i}\left(q_{i} ; \eta_{i}\right)$, so welfare for a given realization of $\theta=\left\{\theta_{1}, \ldots, \theta_{n}\right\}$ and $\eta=\left\{\eta_{1}, \ldots, \eta_{n}\right\}$ is equal to

$$
W(\theta, \eta)=\sum_{i=1}^{n}\left[S_{i}\left(q_{i} ; \theta_{i}\right)-C_{i}\left(q_{i} ; \eta_{i}\right)\right]-D(e)
$$

where $e=\sum_{i=1}^{n} q_{i}$.

An OBA scheme $\left\{\bar{e}, \alpha_{1}, \ldots, \alpha_{n}\right\}$ includes a fraction of $\bar{e}$ auctioned permits and OBA rates $\alpha_{i} \in[0,1)$ for each sector $i=1, \ldots, n$, so the total number of permits in the market will be $e=\bar{e}+\sum_{i=1}^{n} \alpha_{i} q_{i}$. The output market in each sector will clear at the price $p_{i}$ that equals marginal production costs minus the OBA subsidy

$$
p_{i}=P_{i}\left(q_{i} ; \theta_{i}\right)=C_{i}^{\prime}\left(q_{i} ; \eta_{i}\right)+r-\alpha_{i} r
$$

where $r$ is permit price (common to all sectors) and $C_{i}^{\prime}(\cdot)$ is sector $i$ 's marginal cost. Thus, the market equilibrium is described by $n+1$ equations

$$
\begin{aligned}
\sum_{i=1}^{n}\left(1-\alpha_{i}\right) q_{i} & =\bar{e} \\
P_{i}\left(q_{i}, \theta_{i}\right)-C_{i}^{\prime}\left(q_{i} ; \eta_{i}\right) & =\frac{1-\alpha_{i}}{1-\alpha_{1}}\left[P_{1}\left(q_{1}, \theta_{1}\right)-C_{1}^{\prime}\left(q_{1} ; \eta_{1}\right)\right]
\end{aligned}
$$

for all $i=1, \ldots, n$.

Lemma 3 Any scheme $\left\{\bar{e}, \alpha_{1}, \ldots, \alpha_{n}\right\}$ with $\alpha_{i} \in[0,1)$ is equivalent (i.e., it leads to the same equilibrium outcome and payoffs) to a scheme in which the lowest OBA rate is normalized to zero

$$
\left\{\frac{\bar{e}}{1-\alpha_{j}}, \frac{\alpha_{1}-\alpha_{j}}{1-\alpha_{j}}, \ldots, \frac{\alpha_{j-1}-\alpha_{j}}{1-\alpha_{j}}, 0, \frac{\alpha_{j+1}-\alpha_{j}}{1-\alpha_{j}}, \ldots, \frac{\alpha_{n}-\alpha_{j}}{1-\alpha_{j}}\right\}
$$

where $\alpha_{j}=\min _{i} \alpha_{i}$.

Proof. It is easy to see that both schemes satisfy equations (18) and (19), which implies that output levels are identical under both schemes for all demand states. In addition, the net emission price $\left(1-\alpha_{i}\right) r$ in sector $i$ is identical to the price under scheme (20); more precisely, the permit price under the new scheme is $\left(1-\alpha_{j}\right)$ times the permit price under the original scheme. Given the equivalence in output and price levels, profits and consumer surplus must be identical across schemes.

Although it appears from the lemma that the regulator has some room to change OBA rates across sectors without welfare consequences, the reality is that she has none because 20 is just one of the many price normalizations she can pick, ${ }^{14}$ any of which with the same distribution implications. Hence, one can theoretically consider schemes with negative OBA rates, since, any such scheme could be transformed into an equivalent scheme with positive OBA rates for all sectors.

\footnotetext{
${ }^{14}$ Notice that no normalization can violate the constraint $\alpha_{i}<1$. Setting $\alpha_{i}=1$, for example, is equivalent to removing sector $i$ from the permit regulation.
} 
When it comes to choosing the optimal OBA scheme, the same tension detected in the single-sector appears in this multiple-sector setting: letting the overall cap on emissions to adjust to shocks comes at an inefficiency cost. The inefficiency here is a misallocation of the cap across sectors. Sectors with relatively higher OBA rates produce and pollute too much. In fact, the welfare impact of increasing the OBA rate in one sector, say $k$, is given by

$$
\frac{\partial \tilde{W}}{\partial \alpha_{k}}=\mathbb{E}\left[\left(r-D^{\prime}(e)\right) q_{k}-D^{\prime}(e) \sum_{i=1}^{n} \alpha_{i} \frac{\partial q_{i}}{\partial \alpha_{k}}\right]
$$

where $e=\sum_{i=1}^{n} q_{i}=\bar{e}+\sum_{i=1}^{n} \alpha_{i} q_{i}$.

The first term in (21) captures the direct effect of increasing emissions in sector $k$ by increasing $\alpha_{k}$. This term is expected to be positive if $q_{k}$ is larger when $r-D^{\prime}(e)>0$. The second term represents the effect of the change in production, not only in sector $k$ but in all sectors. Increasing production in a sector $i$ has a net effect of $\alpha_{i} D^{\prime}(e)$, which is the sum of the loss $\alpha_{i} r$ due to the subsidy of production and the gain $\alpha_{i}\left(r-D^{\prime}\right)$ of increasing emissions. This term can be positive, since production in a sector $i \neq k$ might well decrease with respect to $\alpha_{k}$.

Expression (21) tells us right away that setting $\alpha_{i}=0$ for all sectors cannot be optimal if there is just one sector that exhibits a correlation different from zero between output and permit prices. Notice that a negative correlation would in principle call for a negative OBA rate in that sector, but according to Lemma 3 , this would be equivalent to set a null OBA rate in that sector and positive rates in all others. In any case, the presence of multiple sectors makes the optimality of an OBA scheme certain (unless all sectors are equal, which takes us back to Proposition 1).

Proposition 3 An optimal $O B A$ scheme $\left\{\bar{e}, \alpha_{1}, \ldots, \alpha_{n}\right\}$ satisfies the following system of equations

$$
\begin{aligned}
\mathbb{E}\left[r-D^{\prime}(e)\right] & =\mathbb{E}\left[D^{\prime}(e) \frac{-\partial r}{\partial \bar{e}} \sum_{i=1}^{n} \alpha_{i} \frac{1-\alpha_{i}}{C_{i}^{\prime \prime}-P_{i}^{\prime}}\right] \\
\operatorname{cov}\left(\frac{\partial W}{\partial \bar{e}}, q_{k}\right) & =\mathbb{E}\left\{D^{\prime}(e) \frac{r}{C_{k}^{\prime \prime}-P_{k}^{\prime}} \frac{-\partial r}{\partial \bar{e}} \sum_{i=1}^{n}\left[\frac{1-\alpha_{i}}{C_{i}^{\prime \prime}-P_{i}^{\prime}}\left(\alpha_{k}-\alpha_{i}\right)\right]\right\}
\end{aligned}
$$

for all $k=1, \ldots, n$.

Proof. See Appendix B.1.

Equation (22) is similar to equation (8) in Proposition 1. It says that the optimal number of auctioned permits, $\bar{e}$, should be adjusted to the allocation of OBA permits, so as to keep a difference between permit prices and marginal harm equal to the marginal inefficiency cost generated by these OBA permits. If for some reason it is optimal to set all OBA rates equal to zero, then 22 reduces to the standard optimality condition that expected permit prices should be equal to marginal harm, i.e., $\mathbb{E}[r]=D^{\prime}(e=\bar{e})$.

Equation (23) also follows a similar logic than equation (9) in Proposition 1. Increasing the OBA rate in sector $k$ could be decomposed in two effects: it is like auctioning $q_{k}$ more permits and shifting the demand for permits in sector $k$. But we know that when the total 
number of auctioned permits $\bar{e}$ is optimally set, the expected marginal (social) value of an extra auctioned permit in the market across all demand states is null (this applies regardless of whether we have one or multiple sectors). This implies that only the covariance matters for the first effect (i.e., the effect of auctioning additional permits) to have a positive welfare impact.

The right-hand-side of (23) can be interpreted as the marginal effect of $\alpha_{k}$ on the misallocation of the total cap when $\alpha_{i}$ 's differ across sectors. The effect of $\alpha_{k}$ on the distorted allocation is a weighted difference between the OBA rate in sector $\alpha_{k}$ and the remaining sectors. Contrary to the single sector case, this effect could be negative, increasing the OBA rate in a particular sector might actually reduce distortions associated to other OBA rates.

Without uncertainty, one can see from equation (23) that it would be optimal to set all $\alpha_{i}$ equal which is equivalent to not introducing an OBA scheme. The benefit from introducing an OBA scheme necessarily requires some covariance, in at least one sector, between the benefit/cost of auctioning one extra permit in a state and the number of permits actually injected in that state.

The main difference between Propositions 1 and 3 rests on the multidimensionality of the scheme, so that one cannot, and does not need to, perform a "positive correlation test" as in Proposition 1 to determine whether a sector requires a positive OBA rate. It might be optimal to set a strictly positive OBA rate in a particular sector whatever the sign of the covariance of its output with the marginal benefits from an auctioned permit is.

The main message from Proposition 3 is that setting $\alpha_{k}=0$ (or $\alpha_{k}=\alpha_{i}$ ) for all sectors is very unlikely. It would only happen if $\operatorname{cov}\left(\partial W / \partial \bar{e}, q_{k}\right)=0$ for all $k$. It is easy to rule this out; it suffices to have sectors receiving different shocks. To fully appreciate this, and get some more palatable results, a linear specification is considered next. The linear specification will also serve as the basis for the numerical exercises in the following section.

\subsection{A linear set-up}

For tractability, and without much loss of generality, in what follows we work with linear functions and shocks that only affect demand, which in addition are assumed to be independently distributed and to enter additively 15 In particular, we let

$$
D^{\prime}(e)=h, p_{i}\left(q_{i}, \theta_{i}\right)=a_{i}+\theta_{i}-b_{i} q_{i} \text { and } C_{i}\left(q_{i}\right)=\gamma_{i} q_{i}^{2} / 2
$$

for all $i=1 \ldots n$, where $a_{i}, b_{i}, \gamma_{i}$ are all strictly positive, and $\mathbb{E}\left[\theta_{i}\right]=0, \mathbb{E}\left[\theta_{i}^{2}\right]=\sigma_{i}^{2}>0$ and $\operatorname{cov}\left(\theta_{i}, \theta_{j}\right)=0$. We also assume that shocks are such that there is always an interior solution, that is, that there is always a positive level of output in all sectors for all possible shocks and regulatory designs.

Under this linear specification, it is possible to fully describe and compute the optimal OBA scheme of Proposition 3 .

Proposition 4 Under the linear specification described above, the optimal OBA scheme considers $O B A$ rates increasing with sector volatility $\left(\sigma_{i}\right)$ and market size $\left(1 / \beta_{i}\right.$, where $\beta_{i}=$

\footnotetext{
${ }^{15}$ We could have alternatively considered shocks on the supply side (e.g., $C_{i}=\eta_{i} q_{i}+\gamma_{i} q_{i}^{2} / 2$ ). In this linear world, it is irrelevant whether shocks are on the demand or production side.
} 
$\left.b_{i}+\gamma_{i}\right)$, that is, $\alpha_{k}>\alpha_{l}$ if $\sigma_{k}^{2} / \beta_{k}>\sigma_{l}^{2} / \beta_{l}$ for any $l \neq k=1, \ldots, n$. If sector 1 is defined as $\sigma_{1} / \beta_{1}=\min _{i} \sigma_{i}^{2} / \beta_{i}$, then an optimal OBA scheme is characterized by (i) $\alpha_{1}=0$, (ii)

$$
\alpha_{k}=\frac{\Delta_{k}}{\Delta_{k}+\Psi}
$$

where

$$
\Delta_{k}=\frac{1}{h^{2}}\left[\frac{\sigma_{k}^{2}}{\beta_{k}}-\frac{\sigma_{1}^{2}}{\beta_{1}}\right]
$$

and $\Psi$ is the unique positive solution to $x$ in equation $\sum_{i=1}^{n}\left[\beta_{i}\left(\Delta_{i}+x\right)\right]^{-1}=1$, and (iii) a number of auctioned permits $\bar{e}$ such that

$$
\mathbb{E} r=\frac{\sum_{i}\left(1-\alpha_{i}\right) / \beta_{i}}{\sum_{i}\left(1-\alpha_{i}\right)^{2} / \beta_{i}} h
$$

Proof. See Appendix B.2.

This proposition shows quite clearly that what matters for OBA is not the absolute volatility but the relative volatility between sectors, after controlling for sector size. In fact, expression (26) indicates that the optimal design remains unchanged if the volatility in all sectors, measured by $\sigma^{2} / \beta$, change by the same amount. This relative volatility is what generates a covariance between permit prices and output. Suppose there are only two sectors, 1 and 2, with $\sigma_{2}^{2} / \beta_{2}>\sigma_{1}^{2} / \beta_{1}$. If the regulator allocates an optimal number of permits $\bar{e}$ together with $\alpha_{1}=\alpha_{2}=0$, total output will be fixed, $q_{1}+q_{2}=\bar{e}$, but it would split between the two sectors depending on the specific shocks affecting them. This output adjustment leads to changes in permit prices $r$ and, ultimately, to a positive covariance between permit prices and output in sector 2.

Proposition 4 also helps us to visualize more precisely the impact of changes in market conditions, for example, of adding a (volatile) sector to the regulation or of increasing the volatility of one particular sector or of a group of sectors. The first change is straightforward to evaluate. Since adding a sector would increase $\Psi$, this will reduce the OBA rates in all existing sectors.

In this $n$-sector (linear) model it is relatively easy to compute profit and welfare gains from implementing an (optimal) OBA scheme vis-a-vis the simple permit scheme of Lemma 1. The numerical exercises in Section 4 shows that these gains can be indeed substantial even for volatility levels that are not that large. These gains, however, introduce the regulator to an implementation problem as seen in the carbon market in Europe: sectors want to lobby for larger OBA rates. We turn to this implementation problem now.

\subsection{Self selection}

Not only in the carbon market in Europe, but allocating free permits to firms or sectors is always controversial and subject to an intense amount of lobbying activity. We expect an OBA scheme to be no different. For instance, if the regulator announces the OBA scheme of Proposition 4 all sectors would lobby to get the highest available OBA rate. Therefore, even if the regulator is able to identify the characteristics of each sector well, political reality may prevent her to discriminate among sectors and implement the optimal OBA scheme. We will 
show that there is a simple way for the regulator to go around this selection problem while preserving the optimal OBA outcome of Proposition 4 to use a fraction of the auctioned permits $\bar{e}$ to construct a menu of OBA rates and lump-sum allocations that can sort out sectors. This allocation mechanism should be viewed as a stylized representation of the negotiation taking place between the regulator and regulated sectors. Alternatively, one can view this mechanism as the solution to a standard adverse selection problem in which sector's characteristics, most notably volatility and costs, are unknown to the regulator, so the regulator needs to communicate with sectors before designing the regulation.16

Our analysis builds upon the linear specification of the previous section. Since sector volatility is our central problem here, we will work with sectors that are identical except for their volatility: $a_{i}=a, b_{i}=b$ and $\gamma_{i}=\gamma$ for all $i=1, \ldots, n$ and $\sigma_{1}<\ldots<\sigma_{i}<\ldots \sigma_{n}$. The regulator offers a menu of permit-allocation options $\left\{\left(\alpha_{j}, \hat{e}_{j}\right) / j=1, \ldots, n\right\}$, where $\alpha_{j}$ is the OBA rate in option $j$ and $\hat{e}_{j}$ is the number of free lump-sum permits in that option. Whenever $\sum_{j} \hat{e}_{j}<\bar{e}$, the regulator auctions the remaining fraction $\bar{e}-\sum_{j} \hat{e}_{j}$. Since negotiations take place at the sectorial level, all firms within a sector that goes for option $j=1, \ldots, n$ will receive the same allocation $\left(\alpha_{j}, \hat{e}_{j}\right)$. Sectors anticipate the effect of different OBA rates on their profit while taking the permit price $r$ as given.

We want to determine conditions under which the optimal scheme could be indeed implemented via such a menu, that is, under which conditions the menu satisfies both (i) the balanced-budget constraint $\sum_{j} \hat{e}_{j} \leq \bar{e}$ and (ii) the self-selection constraints

$$
\mathbb{E}\left[\pi_{i}\left(\theta_{i}, r, \alpha_{i}\right)+r \hat{e}_{i}\right] \geq \mathbb{E}\left[\pi_{i}\left(\theta_{i}, r, \alpha_{j}\right)+r \hat{e}_{j}\right]
$$

for all $i=1, \ldots, n$ and $j \neq i$, where

$$
\pi_{i}\left(\theta_{i}, r, \alpha\right)=\frac{\gamma}{2 \beta^{2}}\left[a+\theta_{i}-(1-\alpha) r\right]^{2}
$$

is sector $i$ 's profit gross of permit transfers for a given level of demand $\theta_{i}$, permit price $r$ and OBA rate $\alpha$.

Let us focus first on what it takes for the self-selection constraints to hold. This requires to establish the existence of something equivalent to a single-crossing property. Thus, take two adjacent sectors, say $\theta_{i}$ and $\theta_{i+1}$, and ask which of the two is willing to pay more for a marginal increase in the OBA rate from any given level $\alpha$. Differentiating sectors' payoffs with respect to $\alpha$ and taking the difference yields

$$
\mathbb{E}\left[\frac{\partial \pi_{i+1}\left(\theta_{i+1}, r, \alpha\right)}{\partial \alpha}\right]-\mathbb{E}\left[\frac{\partial \pi_{i}\left(\theta_{i}, r, \alpha\right)}{\partial \alpha}\right]=\frac{\gamma}{\beta^{2}} \mathbb{E}\left[r\left(\theta_{i+1}-\theta_{i}\right)\right]
$$

We want to establish the conditions under which this difference is positive, so that sector $i+1$ is willing to pay more than sector $i$ for the marginal increase at any possible level $\alpha$. This latter is what will allow us to separate sectors. For instance, if sector $n-1$ needs to

\footnotetext{
16 Martimort and Sand-Zantman (2015) also study a problem of adverse selection as applied to climate change policy. One main difference with that article is that here it is mandatory for polluters to comply with the regulation. Another is that we allow initial permit allocations to be tradable. We do share with them the possibility of implementing the (full-information) optimal scheme as long as the budget-balanced constraint is not binding.
} 
be compensated in $\Delta$ to take its equilibrium rate $\alpha_{n-1}$ instead of the highest rate $\alpha_{n}$, then sector $n-2$ needs to be compensated in strictly less than $\Delta$ to achieve the same and so on as we considers sectors with lower volatilities.

Since sectors are too small to affect the permit price, we can evaluate the profit changes in (30) at the permit price that will prevail in equilibrium, that is, at the permit price when all sectors take their equilibrium options, which is

$$
r=\frac{\sum_{k=1}^{n}\left[\left(1-\alpha_{k}\right)\left(a+\theta_{k}\right)\right]-\beta \bar{e}}{\sum_{k=1}^{n}\left(1-\alpha_{k}\right)^{2}}
$$

Plugging (31) into (30), it turns out that this latter expression is positive as long as

$$
\left(1-\alpha_{i+1}\right) \sigma_{i+1}^{2}>\left(1-\alpha_{i}\right) \sigma_{i}^{2}
$$

which requires that the OBA rates in the optimal scheme do not grow much faster than the sector volatilities.

It is evident that condition (32) departs from the single-crossing property that we usually encounter in standard models of adverse selection, where the sorting condition depends exclusively on the functional form of the agent's utility and not on the value of a regulatory decision variable. The reason here is different is due to changes in the way a sector volatility affects permit price variations. In the absence of OBA, more volatile sectors have a greater influence on permit price variations. However, as these more volatile sectors get assigned higher OBA rates, their volatility is reduced, and hence, their influence on permit price variations. Condition (32) requires such reduction not be so large in the optimal scheme, so that more volatile sectors continue having a greater influence on permit price variations.

Whether the optimal OBA scheme of Proposition 4 can be indeed implemented not only depends on (32) holding but also on satisfying the budget constraint (i). Thanks to Lemma 3 we do not need to check a potentially large number of menus that could implement the optimal scheme. We can restrict ourselves to menus in which $\alpha_{1}=0$ and $\hat{e}_{n}=0$ since any implementable menu could be transformed into a menu with these two features. Therefore, the menu that can potentially implement the optimal scheme with the minimum number of lump-sum permits being allocated consists in setting $\alpha_{1}=0$ and $\alpha_{i}$ as in Proposition 4 and

$$
\begin{aligned}
\hat{e}_{n} & =0 \\
\hat{e}_{n-1}-\hat{e}_{n} & =\mathbb{E}\left[\pi_{n-1}\left(\theta_{n-1}, r, \alpha_{n}\right)-\pi_{n-1}\left(\theta_{n-1}, r, \alpha_{n-1}\right)\right] / \mathbb{E}[r] \\
\ldots & \\
\hat{e}_{i}-\hat{e}_{i+1} & =\mathbb{E}\left[\pi_{i}\left(\theta_{i}, r, \alpha_{i+1}\right)-\pi_{i}\left(\theta_{i}, r, \alpha_{i}\right)\right] / \mathbb{E}[r]
\end{aligned}
$$

so that each of self-selection constraints holds. Whether $\sum_{j=1}^{n} \hat{e}_{j}$ is smaller than $\bar{e}$ is not immediate, but it is very likely as the next proposition shows.

Proposition 5 Under the linear specification above with sectors that are identical but for their volatility (i.e., $\sigma_{1}<\ldots<\sigma_{n}$ ), the optimal OBA scheme in Proposition 4 can be implemented with a menu of $O B A$ rates and lump-sum allocations $\left\{\left(\alpha_{j}, \hat{e}_{j}\right) / i=1, \ldots, n\right\}$ as described in (33) as long as (i) $a>h(1+2 \gamma / b)$ and (ii) $\sigma_{1}^{2}<h^{2} \sum_{i=1}^{n}\left(1-\alpha_{i}\right)$. 


\section{Proof. See Appendix B.3}

Condition (ii) is obtained from working through the $n-1$ incentive compatibility constraints. According to this condition, it appears that all that is required is to have just one single sector in the permit system with a volatility low enough for all this to work. This should not be interpreted, however, as that all we need is to just bring a low volatility sector to the permit system; the sector must be large enough, like all the others, so that there is always a positive amount of production in the sector for any possible shock and permit price realizations. Arriving at condition (i) is more demanding, but it is also likely to hold in practice. Take the electricity sector for instance. Estimates of the value of lost load, which is a good approximation for $a$ since it corresponds to what customers are willing to pay to avoid a disruption in their electricity service, is many times larger than the corresponding social cost of carbon, i.e., $h$ in our model.

As we will see next, both conditions (i) and (ii) hold easily in our policy exercises, but it is nevertheless useful to explore more formally what would be the additional distortions the regulator will need to introduce to sort sectors out when these two conditions do not hold. Given that the optimal OBA scheme in Proposition 4 is already away from the first-best, it is not clear what are these least-cost extra distortions. Following a bunching-at-the-top solution, one possible option would be to maintain the optimal OBA scheme to all sectors $k<\bar{k}$ and offer the same deal $\left(\alpha_{\bar{k}}, \hat{e}_{\bar{k}}\right)$ to all sectors $k \geq \bar{k}$, where the cutoff $\bar{k}$ is to be found by going down the volatility ladder until $\sum_{j=1}^{n} \hat{e}_{j}=\bar{e}$, while taking into account that $\bar{e}$ is not fixed but endogenously determined along with $\bar{k}$ and the rest of the menu.

\section{$4 \quad$ Policy implications}

In this section we use our model to analyze the consequences of introducing an OBA scheme in permit-trading regulation and discuss its policy implications using a numerical illustration. We take the carbon market in Europe, better known as the EU-ETS, as a background for this discussion (the California market would have offered another illustration with similar policy issues). In the EU-ETS a piece-wise approximation of OBA has been introduced for years 2013-2020 for sectors at risk of leakage while all remaining sectors will receive no free (OBA) allowances (Branger et al., 2015).

The first issue we consider is whether the flexibility in emissions induced by granting OBA permits to some sectors should necessarily lead to some flexibility in the overall cap, as formulated in our analysis. Under the current EU-ETS regulation the total cap, which was set in 2008 at a time of high economic activity, is fixed. The current level of activity has dropped significantly, so the OBA sectors have reduced their emissions but the cap has remained as originally set. This partly explains the drop observed in the carbon price and the current debate on how to eliminate the "excess" of allowances in the market.17 We will show that a flexible total cap would have mitigated this unbalance greatly; furthermore, it would have reduced perverse effects in non-OBA sectors (i.e., sectors for which $\alpha=0$ ) due to the drop in the carbon price.

A second issue we address concerns the difficult question of defining the sectors at risk, i.e.,

\footnotetext{
${ }^{17}$ http://ec.europa.eu/clima/policies/ets/index_en.htm
} 
the sectors that should be entitled to OBA permits. Initially to be eligible for OBA permits, the EU-ETS required a sector to simultaneously exhibit a carbon intensity and exposition to international trade above pre-established thresholds. In the end it required the sector to comply with either requirement. As a result, more than $80 \%$ of industrial emissions (i.e., emissions covered by the EU-ETS except electricity production) became eligible for OBA permits. This has taken the EU to revise its eligibility criteria, which has touched on the many of the issues discussed in the article, including firms' active lobby to remain eligible.

\subsection{A numerical illustration}

The illustration that follows is based on the linear specification of section 3.2 with two sectors with the following numerical values for the parameters: $a_{1}=a_{2}=1, b_{1}=b_{2}=1$, $\gamma_{1}=\gamma_{2}=1, h=1 / 4, \theta_{1}=0$ and $\theta_{2} \in\{-\lambda, \lambda\}$ with equal probability, so $\sigma_{2}=\lambda$. The parameter $\lambda$ will be referred as the level of uncertainty. The model is explored for $\lambda$ moving from 0 to $1 / 2$. We are particularly interested in large values of $\lambda{ }^{18}$

Corollary 1 With the linear specification (24) for two identical sectors but for their volatility $\left(\sigma_{1}=0\right.$ and $\left.\sigma_{2}>0\right)$ the optimal OBA scheme $\left\{\bar{e}, \alpha_{1}, \alpha_{2}\right\}$ reduces to

$$
\begin{aligned}
\alpha_{1} & \in[0,1) \\
\frac{\alpha_{2}-\alpha_{1}}{1-\alpha_{1}} & =1-\left[\left(\Delta^{2}+1\right)^{1 / 2}-\Delta\right]>0 \\
\bar{e} & =\frac{1}{2}(a-h)\left(2-\alpha_{1}-\alpha_{2}\right)
\end{aligned}
$$

where $\Delta=\sigma_{2}^{2} / 2 h^{2}>0$.

Proof. See Appendix B.4.

Corollary 1 provides the relation between $\alpha_{1}$ and $\alpha_{2}$ that must hold under an optimal OBA scheme, so without any loss of generality we focus on $\alpha_{1}=0$. Figure 1 depicts this optimal policy as a function of $\lambda$. It can be observed that the optimal OBA rate is increasing rapidly as the uncertainty level increases. The level of permits to be auctioned off is also depicted, as well as the level of lump-sum permits that should be allocated to sector 1 to make the optimal OBA rate robust to self selection. These values of permits are given in percentage of the cap without OBA, but considering uncertainty. For example, for $\lambda=0.5$ approximately $60 \%$ of the permits should be auctioned off, and to prevent sector 1 to lobby for sector 2's OBA rate, the regulator should give sector 1 a total of $20 \%$ of the permits in a lump-sum transfer, reducing the total number of permits to be auctioned off to $40 \%$. This slacks applies to any level of $\lambda$, as Figure 1 shows.

\footnotetext{
${ }^{18}$ Take the cement market to have some order of magnitude for the level of uncertainty in a given sector. In Branger et al. (2015) it is observed that approximately $50 \%$ of the EU cement market has gone through a severe recession. In countries such as Ireland, Spain and Greece the level of cement consumption in 2012 was around $30 \%$ the corresponding level of 2007, the time at which the EU-ETS had been designed. In our simulation we consider a range for the uncertainty factor of plus or minus $50 \%$, that is a drop of $80 \%$ in consumption relative to the peak.
} 


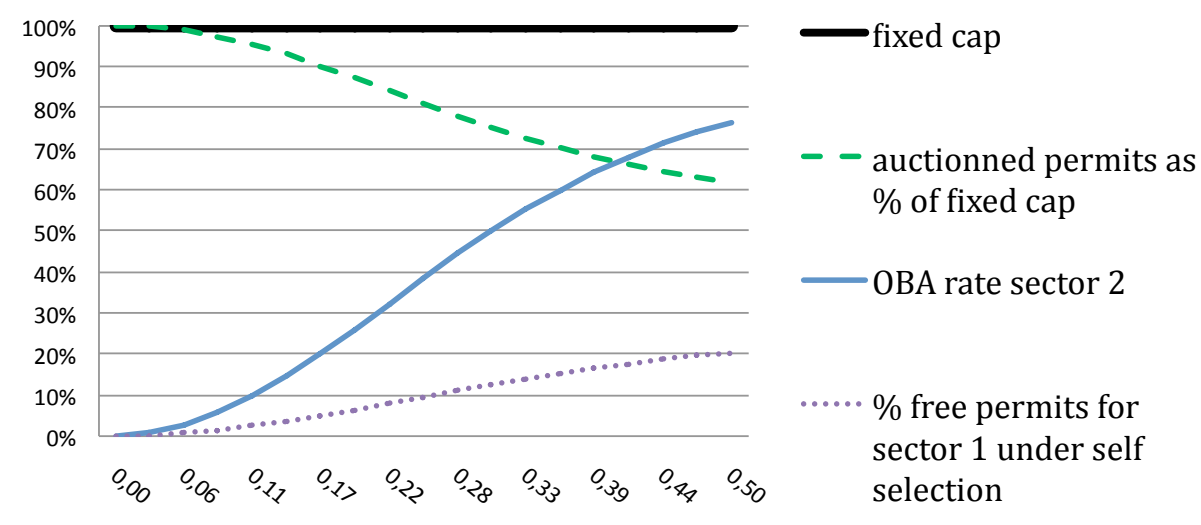

Figure 1: Optimal policy as a function of uncertainty $(\lambda)$

Consider now the welfare associated with the optimal policy. For convenience it will be computed in percentage terms relative to the first-best level of welfare. Figure 2a depicts the total expected welfare, while Figures $2 \mathrm{~b}$ and $2 \mathrm{c}$ depict the welfare in sector 1 and sector 2, respectively. It is interesting to also derive these welfare levels under two other scenarios: a fixed cap without OBA and a fixed cap with OBA. In the latter case we assume that the regulator insists on maintaining a global fixed cap for the total emissions in spite of the fact that she gives OBA permits to sector 2. Formally we compare the following four scenarios.

1. First best (FB): a carbon tax equal to marginal damage, $r=h$. Total emissions are equal to $e=(1-h)+\theta_{2}$. We denote by $\bar{e}_{\mathrm{FB}}=1-h$ the expected amount of emissions under the first-best.

2. Fixed cap \& no $O B A(\mathrm{FCN})$ : a fixed cap is set ex-ante at $\bar{e}_{\mathrm{FB}}$ and $\alpha=0$. The permit price varies with $\theta_{2}$ as follows

$$
r_{\mathrm{FCN}}\left(\theta_{2}\right)=1-\bar{e}_{\mathrm{FB}}+\frac{\theta_{2}}{2}=h+\frac{\theta_{2}}{2}
$$

3. Flexible cap \& $O B A$ (OBA): following Corollary 1, a total number of permits $\bar{e}^{*}$ are auctioned off and sector 2 is assigned an OBA rate equal to $\alpha_{2}^{*}$. The permit price is

$$
r_{\mathrm{OBA}}\left(\theta_{2}\right)=\frac{1+\left(1-\alpha_{2}^{*}\right)\left(1+\theta_{2}\right)-2 \bar{e}^{*}}{1+\left(1-\alpha_{2}^{*}\right)^{2}}
$$

4. Fixed cap $\& O B A$ (FCO) 19 a total number of permits $\bar{e}_{\mathrm{FB}}$ are allocated, so all the OBA permits that are assigned to sector 2 under the rate $\alpha_{2}^{*}$ are substracted from the permits to be auctioned off so as to maintain the overall allocation fixed at $\bar{e}_{\mathrm{FB}}$. The permit price in this case is equal to

$$
r_{\mathrm{FCO}}\left(\theta_{2}\right)=\frac{2+\theta_{2}-2 \bar{e}_{\mathrm{FB}}}{2-\alpha_{2}^{*}}
$$

\footnotetext{
${ }^{19} \mathrm{It}$ is possible to slightly improve this scenario by choosing the amount of permits that maximizes expected welfare given the OBA rate $\alpha_{2}^{*}$. The presence of a suboptimal OBA rate calls for a small relaxation of the cap and does not significantly enhance expected welfare with our simulations.
} 


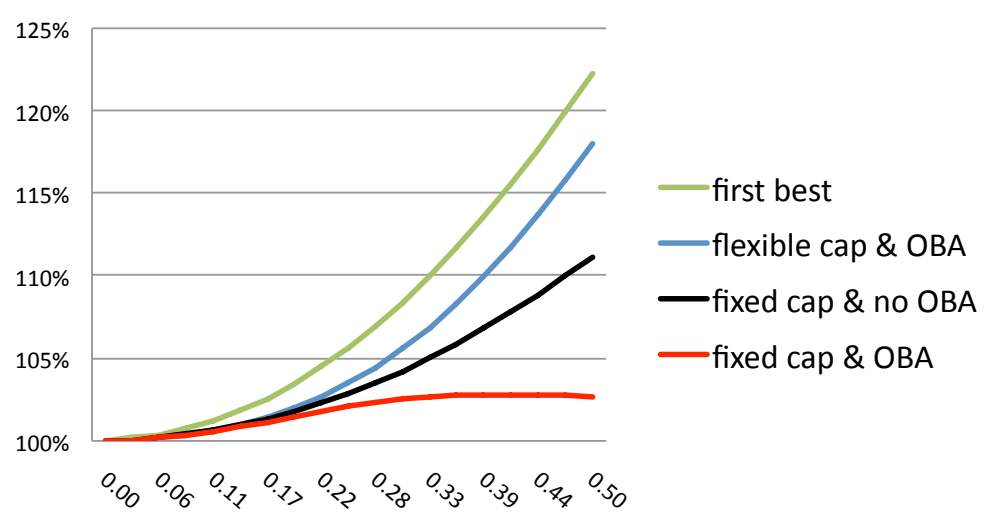

(a) Total

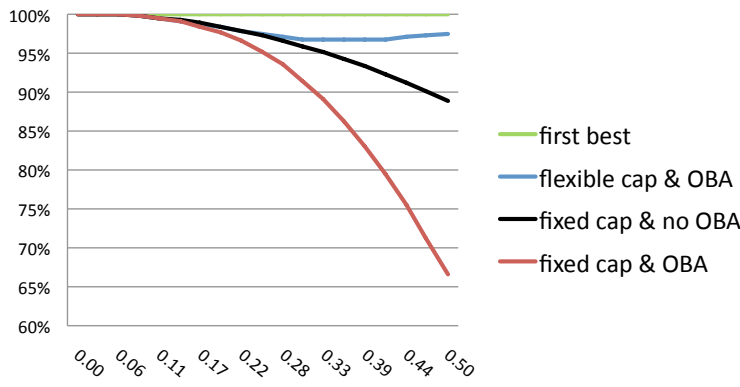

(b) Sector 1

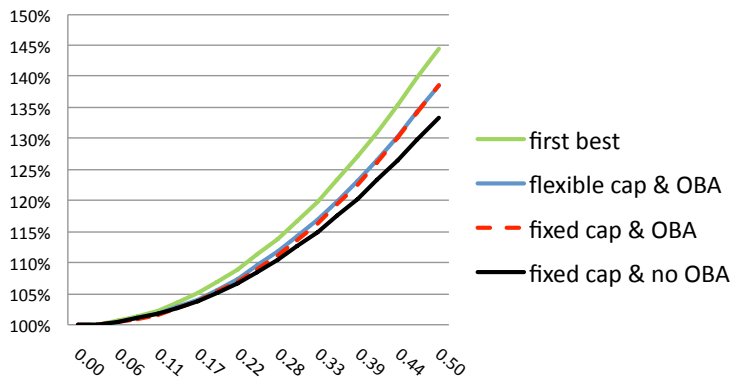

(c) Sector 2

Figure 2: Expected Welfare as a function of uncertainty $(\lambda)$

As it can be easily checked that the volatility of the carbon price will vary accross scenarios, being lowest under an optimal OBA scheme: $\operatorname{var}\left(r_{\mathrm{OBA}}\right)<\operatorname{var}\left(r_{\mathrm{FCN}}\right)<\operatorname{var}\left(r_{\mathrm{FCO}}\right)$. This has important welfare implications as seen in Figures 2a, 2b and 2c. Compare first the situation under a Flexible cap \& OBA (OBA) against the situation under a Fixed cap \& no OBA (FCN). OBA not only improves welfare in sector 2 but also in sector 1 . The reason for this latter is the reduction in the volatility of the carbon price relative to FCN (recall that the first-best calls for a constant carbon price equal to $h$ ). Now, from looking at the situation under a Fixed cap \& OBA (FCO), it is evident that insisting on a global fixed cap increases the volatility of the carbon price even more than under a Fixed cap \& no OBA (FCN), which explains why welfare in sector 1 drops even further. As far as sector 2 is concerned, whether the global cap is fixed or flexible is of a second order effect, the impact of the carbon price is mitigated by the OBA rate. It is well known that introducing OBA in one sector may generate a perverse effect in non-OBA sectors; still this analysis points out that the distortion is conditional on the constraint imposed on the global cap.

The main motivation for insisting on a global fixed cap is certainly political. It is probably easier to agree on (decreasing) levels of global caps than to let the actual observed caps vary depending on the level of economic activity. However, our simple model points out an unexpected consequence if the regulator insists on having a fixed cap. As already mentioned, the observed carbon price will be much more dependent on output levels. Figure 3 depicts the expected emissions with a flexible cap. It is somewhat higher (the ex-post level may be higher or lower) than the corresponding level with a fixed cap; this is the price to pay to 


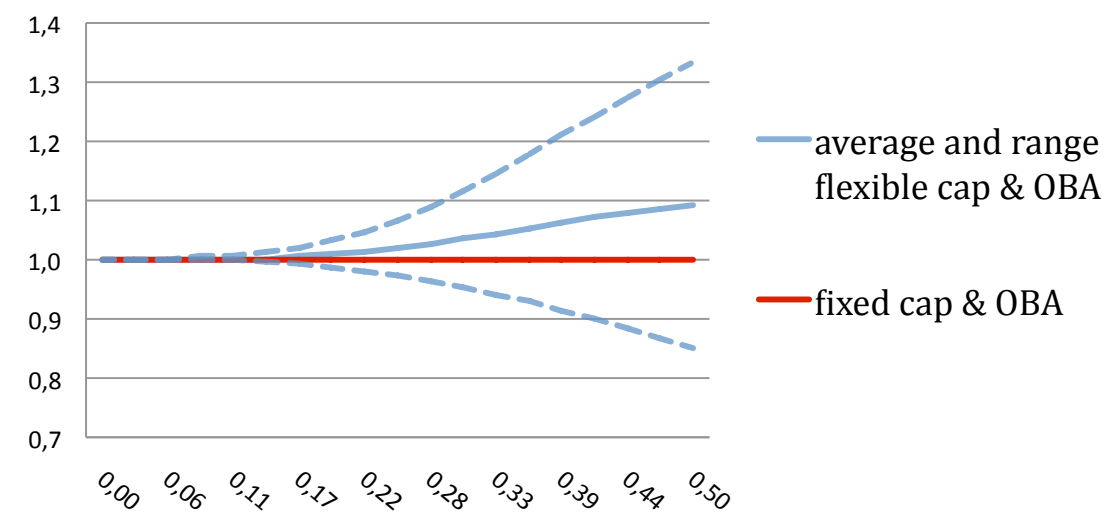

Figure 3: Emissions relative to Fixed cap as a function of uncertainty $(\lambda)$

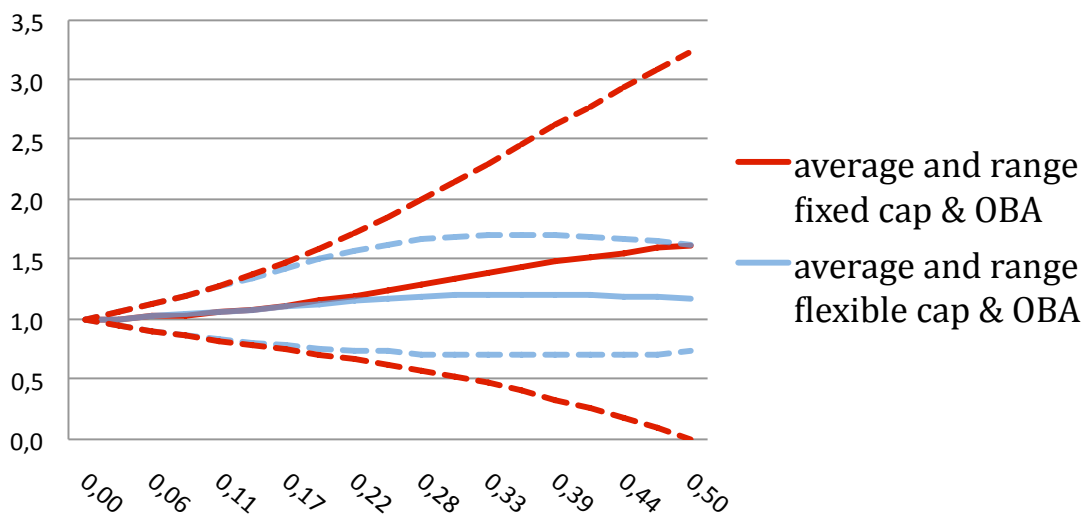

Figure 4: Permit prices relative to the marginal environmental damage $(h)$ as a function of uncertainty $(\lambda)$

increase expected welfare through OBA. More interestingly, Figure 4 gives the associated levels of the permit price. Insisting on a fixed cap makes the permit price to either explode or collapse for large levels of uncertainty. This is consistent with what has been observed in the EU-ETS after the severe recession post 2007-2009.

\subsection{The impact of leakage on the optimal OBA scheme}

This article demonstrates that the optimal OBA rate increases (rapidly) with uncertainty. This should certainly remain true if leakage is introduced into the analysis. While it is outside the scope of this article to extend the general model in such direction, we offer some preliminaries. We extend the linear specification above so as to include two type of firms in sector 2 , a domestic $2 d$ firm and a foreign $2 f$ firm with respective cost functions $C_{2 d}\left(q_{2 d}\right)=\gamma_{2 d} q_{2 d}^{2} / 2$ and $C_{2 f}\left(q_{2 f}\right)=\gamma_{2 f} q_{2 f}^{2} / 2$, with $q_{2}=q_{2 d}+q_{2 f}$. If a carbon price is introduced only in the domestic market this will induce an upward shift in the marginal cost at home, and imports will be relatively cheaper. The ratio $(l)$ of the increase in imports 
to the decrease in domestic production is known as the leakage rate. The leakage ratio is independent of sector 2's demand uncertainty and is simply $l=b_{2} /\left(b_{2}+\gamma_{2 f}\right)$. We keep $b_{2}=\gamma_{2 d}=1$ and use the leakage rate as a variable parameter (which is equivalent to modifying $\left.\gamma_{2 f}\right)$.

The welfare function now writes

$$
W=S_{1}\left(q_{1}\right)-C_{1}\left(q_{1}\right)+S_{2}\left(q_{2} ; \theta_{2}\right)-C_{2 d}\left(q_{2 d}\right)-C_{2 f}\left(q_{2 f}\right)-h\left(q_{1}+q_{2}\right) .
$$

Notice that foreign costs are also included in the welfare function. In order to abstract from any strategic effects, our formulation assumes that the domestic government is buying production at cost from the foreign country. In absence of uncertainty the optimal OBA rate is $\alpha_{2}^{*}=l \cdot{ }^{20}$ Corollary 1 can be directly extended to get the following result

Corollary 2 Under the linear specification above, which considers no uncertainty in sector 1 and is extended to cover foreign competition, the optimal OBA rate for sector 2 is

$$
\alpha_{2}^{*}\left(\sigma_{2}, l\right)=1-\frac{2-l}{2(1-l)}\left[\left(\Delta_{l}^{2}+2 \frac{(1-l)^{2}}{2-l}\right)^{1 / 2}-\Delta_{l}\right]>l
$$

where

$$
\Delta_{l}=\frac{\sigma_{2}^{2}}{h^{2}} \frac{(1-l)^{2}}{2-l}+\frac{1}{2}-\frac{(1-l)^{2}}{2-l}
$$

Proof. See Appendix B.5.

Figure 5 depicts the optimal OBA rate for two values of leakage: a low value $(l=0.2)$ and a high value $(l=0.5)$. It can be seen that the OBA rate increases as the level of uncertainty increases, though naturally at a lower rate for the case of high leakage. This suggests that the level of uncertainty should certainly be introduced as a key factor to determine whether a sector at risk of leakage should benefit or not from output based allocations. For instance, while leakage is low in the cement sector because inland production is somewhat protected from foreign competition, according to this article, its high volatility would be a valid argument to make it eligible for free allocations ${ }^{21}$

\section{Conclusions}

We have studied pollution permit markets in which a fraction of the permits are allocated to firms based on their output. We find that output-based allocations (OBAs), which are receiving increasing attention in the design of carbon markets around the world (e.g., Europe, California, New Zealand) can be optimal under demand and supply volatility despite the output distortions they may create. Take for instance the case of demand volatility and a

\footnotetext{
${ }^{20}$ Consider unregulated foreign production as a function of domestic production $q_{2 f}\left(q_{2 d}\right)$, then, it is as if there is a positive externality associated to domestic production in sector 2 equal to $-l \partial q_{2 f} / \partial q_{2 d}=l \times h$, in addition to the negative externality associated to total emissions.

${ }^{21}$ Notice that the OBA rates under the different leakage rates actually cross for high values of uncertainty $(\lambda=0.5)$. This is so because the leakage rate influences the relative size (in emissions) of the domestic production in sector 2 relative to the size of sector 1 . This somewhat softens the uncertainty effect.
} 


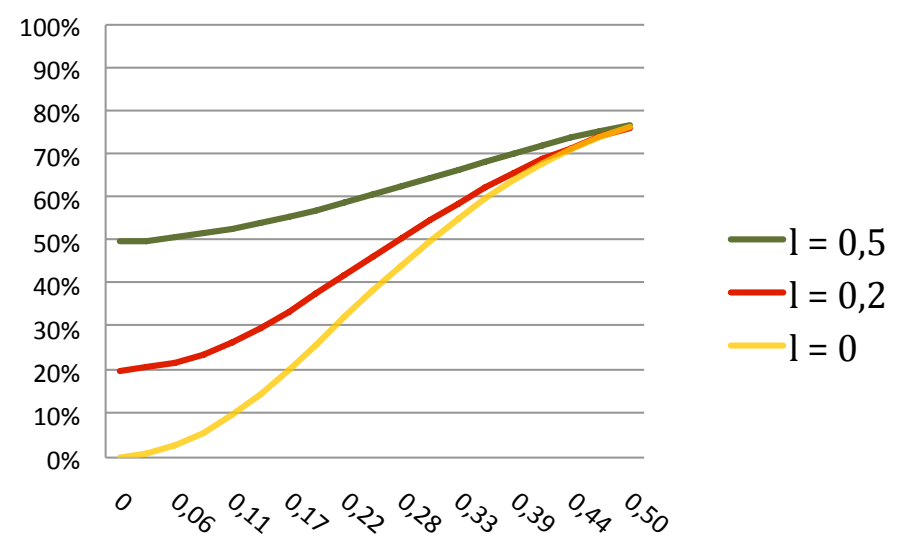

Figure 5: The optimal OBA rate with and without leakage as a function of uncertainty $(\lambda)$

fixed permits cap. For any given realization of demand, the cap is likely to be sub-optimal, being either too low or too high. An OBA scheme introduces some flexibility since the number of permits allocated depends on the level of demand. An OBA scheme enhances welfare by conditioning the emissions cap to economic activity, though imperfectly. This holds whether there is single productive sector covered by the permit market or, even more so, multiple sectors subject to different shocks. Even if a price floor and ceiling are introduced, an OBA scheme still enhances welfare.

Our model provides interesting insights to discuss a number of pending issues for the design of emission trading systems in general and carbon markets in particular. A numerical illustration is used to show the policy relevance of our results. While the introduction of OBA is ordinarily associated with the possibility of leakage in some sectors, we show that uncertainty in those sectors would also call for introducing OBAs. However the benefits associated with OBAs are critically dependent on the simultaneous introduction of some flexibility in the total cap of the corresponding permit market. In absence of this flexibility the volatility of the permit price would be considerably enlarged generating severe distortions in the sectors without OBA. It is also shown that the optimal OBA rate should be much higher than the one derived in models with leakage but without uncertainty. It would be interesting to investigate further these results in a full blown dynamic model in which the regulator commits over a given period of time and shocks occur on a frequent basis. Leakage, heterogeneous abatement technologies, and alternative policy features such as banking and market stability reserves should also be considered.

\section{References}

Berglann, Helge. 2012. "Implementing optimal taxes using tradable share permits." Journal of Environmental Economics and Management, 64(3): 402-409.

Borenstein, Severin, James Bushnell, Frank A Wolak, and Matthew ZaragozaWatkins. 2015. "Expecting the Unexpected: Emissions Uncertainty and Environmental Market Design." Technical report, National Bureau of Economic Research. 
Branger, Frédéric, Jean-Pierre Ponssard, Oliver Sartor, Misato Sato et al. 2015. "EU ETS, Free Allocations, and Activity Level Thresholds: The Devil Lies in the Details." Journal of the Association of Environmental and Resource Economists, 2(3): 401-437.

Branger, Frédéric, and Philippe Quirion. 2014. "Price versus Quantities versus Indexed Quantities." FAERE Working Paper(2014.09): .

Burtraw, Dallas, Karen Palmer, Sophie Pan, and Anthony Paul. 2015. "A Proximate Mirror: Greenhouse Gas Rules and Strategic Behavior under the US Clean Air Act." Resources For the Future, Discussion Papers, 15-02.

Dasgupta, Partha, Peter Hammond, and Eric Maskin. 1980. "On imperfect information and optimal pollution control." The Review of Economic Studies, 47(5): 857-860.

Ellerman, A Denny, and Juan-Pablo Montero. 2007. "The efficiency and robustness of allowance banking in the US Acid Rain Program." The Energy Journal, 28(4): 67-92.

Fischer, C., and A.K. Fox. 2007. "Output-Based Allocation of Emissions Permits for Mitigating Tax and Trade Interactions." Land Economics, 83(4): 575-599.

Fischer, Carolyn. 2011. "Market power and output-based refunding of environmental policy revenues." Resource and Energy Economics, 33(1): 212-230.

Fischer, Carolyn, and Alan K. Fox. 2012. "Comparing policies to combat emissions leakage: Border carbon adjustments versus rebates." Journal of Environmental Economics and Management, 64(2): 199 - 216.

Fowlie, Meredith, Mar Reguant, and Stephen Ryan. 2016. "Market-Based Emissions Regulation and Industry Dynamics." Journal of Political Economy, 124(1): 249-302.

Goulder, Lawrence H, Ian WH Parry, and Dallas Burtraw. 1997. "Revenue-raising versus other approaches to environmental protection: The critical significance of preexisting tax distortions." The Rand Journal of Economics, 28(4): , p. 708.

Kollenberg, Sascha, and Luca Taschini. 2015. "The European Union Emissions Trading System and the market stability reserve: optimal dynamic supply adjustment." Available at SSRN 2610213.

Kossoy, Alexandre, Grzegorz Peszko, Klaus Oppermann, Nicolai Prytz, Noemie Klein, Kornelis Blok, Long Lam, Lindee Wong, and Bra Borkent. 2015. State and trends of carbon pricing 2015.: World Bank and Ecofys, , URL: https://openknowledge. worldbank. org/handle/10986/22630.

Lewis, Tracy R. 1996. "Protecting the environment when costs and benefits are privately known." The RAND Journal of Economics, 27(4): 819-847.

Martimort, David, and Wilfried Sand-Zantman. 2015. "A mechanism design approach to climate-change agreements." Journal of the European Economic Association, DOI: http://dx.doi.org/10.1111/jeea.12150. 
Meunier, Guy, Jean-Pierre Ponssard, and Philippe Quirion. 2014. "Carbon leakage and capacity-based allocations: Is the EU right?." Journal of Environmental Economics and Management, 68(2): $262-279$.

Monjon, Stéphanie, and Philippe Quirion. 2011. "Addressing leakage in the EU ETS: Border adjustment or output-based allocation?." Ecological Economics, 70(11): 19571971.

Montero, Juan-Pablo. 2008. "A simple auction mechanism for the optimal allocation of the commons." The American Economic Review, 98(1): 496-518.

Newell, Richard G, and William A Pizer. 2008. "Indexed regulation." Journal of Environmental Economics and Management, 56(3): 221-233.

Newell, Richard G, William A Pizer, and Daniel Raimi. 2013. "Carbon markets 15 years after Kyoto: Lessons learned, new challenges." The Journal of Economic Perspectives, 27(1): 123-146.

Quirion, Philippe. 2009. "Historic versus output-based allocation of GHG tradable allowances: a comparison." Climate Policy, 9(6): 575-592.

Roberts, Marc J, and Michael Spence. 1976. "Effluent charges and licenses under uncertainty." Journal of Public Economics, 5(3): 193-208.

Rubin, Jonathan D. 1996. "A model of intertemporal emission trading, banking, and borrowing." Journal of Environmental Economics and Management, 31(3): 269-286.

Schmalensee, Richard, Paul L Joskow, A Denny Ellerman, Juan Pablo Montero, and Elizabeth M Bailey. 1998. "An interim evaluation of sulfur dioxide emissions trading." The Journal of Economic Perspectives, 12(3): 53-68.

Spulber, Daniel F. 1988. "Optimal environmental regulation under asymmetric information." Journal of Public Economics, 35(2): 163-181.

Sterner, Thomas, and Lena Höglund Isaksson. 2006. "Refunded emission payments theory, distribution of costs, and Swedish experience of NOx abatement." Ecological Economics, 57(1): 93-106.

Weitzman, M.L. 1974. "Prices vs. Quantities." Review of Economic Studies, 41(4): 477491. 


\section{Appendix}

\section{A Single-sector case}

\section{A.1 Equilibrium}

To characterize the equilibrium for any demand-supply state $\theta-\eta$ we first need to establish how the demand for auctioned permits $\bar{e}$ changes with $r$. Take any $r>0$, the equilibrium is fully characterized by the first-order conditions (5) and (6). Let $f(\alpha, r, \theta, \eta)$ and $g(\alpha, r, \theta, \eta)$ be the unique production and pollution levels, respectively, that solve the two first-order conditions.

Result A1. The demand for auctioned permits $g-\alpha f$ is decreasing in $r$.

Proof. Take the derivative of the first-order conditions (5) and (6) with respect to $r$ :

$$
\left[\begin{array}{cc}
P_{q}-C_{q q} & -C_{q e} \\
-C_{q e} & -C_{e e}
\end{array}\right]\left[\begin{array}{l}
f_{r} \\
g_{r}
\end{array}\right]=\left[\begin{array}{c}
-\alpha \\
1
\end{array}\right]
$$

so that the effects of a change in the permit price on production and emissions are:

$$
\left[\begin{array}{c}
f_{r} \\
g_{r}
\end{array}\right]=\frac{1}{\delta_{1}}\left[\begin{array}{c}
C_{q e}+\alpha C_{e e} \\
\left(P_{q}-C_{q q}\right)-\alpha C_{q e}
\end{array}\right]
$$

where $\delta_{1}=\left(C_{q q}-P_{q}\right) C_{e e}-C_{q e}^{2}$ is strictly positive by assumption $(1)$. The derivative of the net demand for (auctioned) permits is then:

$$
\begin{aligned}
g_{r}-\alpha f_{r} & =\frac{-1}{\delta_{1}}\left[-P_{q}+C_{q q}+2 \alpha C_{q e}+\alpha^{2} C_{e e}\right] \\
& \leq \frac{-1}{\delta_{1}}\left[-P_{q}+C_{q q}-2 \alpha \sqrt{C_{q q} C_{e e}}+\alpha^{2} C_{e e}\right] \\
& \leq \frac{-1}{\delta_{1}}\left[-P_{q}+\left(C_{q q}^{1 / 2}-\alpha C_{e e}^{1 / 2}\right)^{2}\right]<0
\end{aligned}
$$

where the second inequality is thanks to (1)

The equilibrium permit price depends on $\alpha, \bar{e}$ and shocks $\theta$ and $\eta$ according to the function $r(\alpha, \bar{e}, \theta, \eta)$, which is the unique solution of $g(\alpha, r, \theta, \eta)-\alpha f(\alpha, r, \theta, \eta)=\bar{e}$.

The equilibrium levels of output and emissions, $q(\alpha, \bar{e}, \theta, \eta)$ and $e(\alpha, \bar{e}, \theta, \eta)$ respectively, are the (unique) solution of the system of equations:

$$
\begin{array}{r}
P(q, \theta)-C_{q}(q, e, \eta)-\alpha C_{e}(q, e, \eta)=0 \\
\alpha q+\bar{e}=e
\end{array}
$$

For the comparative static of this equilibrium, first introduce

$$
\delta_{2}=-P_{q}+C_{q q}+2 \alpha C_{q e}+\alpha^{2} C_{e e}>0 .
$$

See proof of Result A1 for the sign of $\delta_{2}$. Let us now consider in turn the influence of $\bar{e}, \alpha$ and the shocks $\theta$ and $\eta$ on both $q$ and $e$. 
1. The influence of $\bar{e}$ is given by:

$$
\left[\begin{array}{c}
q_{\bar{e}} \\
e_{\bar{e}}
\end{array}\right]=\frac{1}{\delta_{2}}\left[\begin{array}{c}
\left.-C_{q e}-\alpha C_{e e}\right) \\
q\left(C_{q q}+\alpha C_{q e}-P_{q}\right)
\end{array}\right]
$$

For small values of $\alpha$ both signs are positive. For large values of $\alpha$ there is a counteracting effect via the subsidy and free allocations. With a larger number of auctioned permits the permit price is lower (see Result A1 above) and so is the OBA subsidy. This latter effect can more than offset the increase in production that results from the lower production cost associated to cheaper permits.

2. The influence of $\alpha$ is given by:

$$
\left[\begin{array}{c}
q_{\alpha} \\
e_{\alpha}
\end{array}\right]=\frac{1}{\delta_{2}}\left[\begin{array}{c}
-C_{e}-q\left(C_{q e}+\alpha C_{e e}\right) \\
-\alpha C_{e}+q\left(C_{q q}+\alpha C_{q e}-P_{q}\right)
\end{array}\right]=-\frac{C_{e}}{\delta_{2}}\left[\begin{array}{c}
1 \\
\alpha
\end{array}\right]+q\left[\begin{array}{c}
q_{\bar{e}} \\
e_{\bar{e}}
\end{array}\right]
$$

In both lines the first term comes from the subsidy component of the scheme, and the second term is the effect via the increase in the number of permits, which is equal to the effect of the quantity of auctioned permits times output.

3. The influence of $\theta$ is given by:

$$
\left[\begin{array}{l}
q_{\theta} \\
e_{\theta}
\end{array}\right]=\frac{P_{\theta}}{\delta_{2}}\left[\begin{array}{l}
1 \\
\alpha
\end{array}\right]
$$

Both quantities are increasing in $\theta$. However, the monotonicity of the permit price is not that clear as the next expression shows:

$$
r_{\theta}=-C_{q e} q_{\theta}-C_{e e} e_{\theta}=\frac{P_{\theta}}{\delta_{2}}\left[-C_{q e}-\alpha C_{e e}\right]
$$

The first term in the brackets is positive but the second one is negative and comes from the OBA subsidy. If demand increases and $\alpha$ is large, an increase in the number of OBA permits can more than compensate the pressure on marginal abatement cost coming from a higher output.

4. Finally, the influence of $\eta$ is given by:

$$
\left[\begin{array}{l}
q_{\eta} \\
e_{\eta}
\end{array}\right]=\frac{-C_{q \eta}-\alpha C_{e \eta}}{\delta_{2}}\left[\begin{array}{l}
1 \\
\alpha
\end{array}\right]
$$

Both quantities change in the same direction with respect to $\eta$, because of their relationship with the fixed quantity of auctioned permits: emissions can increase only if production increases and more permits are emitted. The sign of the monotonicity depends on the sign of the influence of $\eta$ on the marginal production cost and the subsidy. For $\alpha=0$ only the former matters. On the other hand, the influence of $\eta$ on the permit price is the sum of a term related to the direct effect of $\eta$ on abatement costs and a term related to the adjustment of production and emissions. At $\alpha=0$ we have

$$
\left.r_{\eta}\right|_{\alpha=0}=-C_{e \eta}-C_{q e} q_{\eta}-C_{e e} e_{\eta}=-C_{e \eta}+C_{q e} \frac{C_{q \eta}}{\delta_{2}}
$$




\section{A.2 Proof of Lemma 2}

We first prove that the covariance of two increasing functions of a random variable is positive.

Result A2. If $\phi$ and $\psi$ are two real valued strictly increasing functions of $\theta$ then $\operatorname{cov}(\phi(\theta), \psi(\theta))>0$.

Proof. Consider a second random variable $\epsilon$ independent from $\theta$ with the same distribution; then

$$
2 \operatorname{cov}(\phi(\theta), \psi(\theta))=\operatorname{cov}(\phi(\theta), \psi(\theta))+\operatorname{cov}(\phi(\epsilon), \psi(\epsilon))=\operatorname{cov}(\phi(\theta)-\phi(\epsilon), \psi(\theta)-\psi(\epsilon))
$$

and $\operatorname{cov}(\phi(\theta)-\phi(\epsilon), \psi(\theta)-\psi(\epsilon))=\mathbb{E}[(\phi(\theta)-\phi(\epsilon)) \times(\psi(\theta)-\psi(\epsilon))]$ and $\forall(\theta, \epsilon) \epsilon$ $\left[\theta_{\min }, \theta_{\max }\right]^{2}$ the product $(\phi(\theta)-\phi(\epsilon)) \times(\psi(\theta)-\psi(\epsilon))$ is positive and strictly so if $\theta \neq \epsilon$.

We now use the comparative static on $\theta$ and $\eta$ performed in Appendix A.1 to establish the following:

- Case 1: $P_{\theta}>0$ and $C_{\eta}=0$. From equations (43) and (44), $r$ and $q$ are both increasing in $\theta$ and invariant to changes in $\eta$. This latter implies that $\operatorname{cov}(r, q)>0$, so from Proposition 1 we have that a small increase in $\alpha$ above 0 augments welfare.

- Case 2: $P_{\theta}=0, C_{q \eta}>0$ and $C_{e \eta}>0$. From (45) and (46), $r$ and $q$ are both decreasing in $\eta$, so they covary, which, from Proposition 1, indicates that a small increase in $\alpha$ above 0 augments welfare.

- Case 3: $P_{\theta}=0, C_{q \eta}>0$ and $-C_{e \eta}>-C_{q e} C_{q \eta} /\left(-P_{q}+C_{q q}\right)$. From (45) and (46), $q$ is decreasing in $\eta$ but and $r$ is increasing in it, so $\operatorname{cov}(r, q)<0$. Consequently, a small increases in $\alpha$ decreases welfare.

\section{B Multi-sector case}

\section{B.1 Proof of Proposition 3}

\section{Preliminaries}

To ease the presentation we will omit the shocks $\theta$ and $\eta$, unless otherwise necessary to avoid confusion. We will first determine how equilibrium output and permit prices vary with respect to $\bar{e}$ and OBA rates. For that, let us introduce the sectorial residual demand $Q_{i}(t)$, which is the unique solution of $P_{i}\left(x_{i}\right)-C_{i}^{\prime}\left(x_{i}\right)=t$. For each sector $i=1, \ldots, n$, the function $Q_{i}($.$) is positive, decreasing and differentiable with Q_{i}^{\prime}=1 /\left(P_{i}^{\prime}-C_{i}^{\prime \prime}\right)$. At the market equilibrium, sector $i$ 's output is $q_{i}=Q_{i}\left(\left(1-\alpha_{i}\right) r\right)$.

The equilibrium permit price is a function $r\left(\bar{e}, \alpha_{1}, . ., \alpha_{n}\right)$ that solves the equation

$$
\sum_{i}\left(1-\alpha_{i}\right) Q_{i}\left(\left(1-\alpha_{i}\right) r\right)=\bar{e}
$$

Taking the derivative of 47 with respect to $\bar{e}$ gives

$$
r_{\bar{e}}=\left[\sum_{i}\left(1-\alpha_{i}\right)^{2} Q_{i}^{\prime}\right]^{-1}
$$


and with respect to $\alpha_{k}$ for $k=1, \ldots, n$

$$
\sum_{i}\left(1-\alpha_{i}\right)^{2} Q_{i}^{\prime} r_{\alpha_{k}}=Q_{k}+\left(1-\alpha_{k}\right) r Q_{k}^{\prime}
$$

SO

$$
r_{\alpha_{k}}=r_{\bar{e}}\left[q_{k}+\left(1-\alpha_{k}\right) r Q_{k}^{\prime}\right] .
$$

On the other hand, changes in equilibrium output wrt to $\bar{e}$ and OBA rates are given by

$$
q_{i \bar{e}}=\left(1-\alpha_{i}\right) Q_{i}^{\prime} r_{\bar{e}}
$$

and

$$
\begin{aligned}
q_{i k} & \equiv \frac{\partial q_{i}}{\partial \alpha_{k}}=\left(1-\alpha_{i}\right) Q_{i}^{\prime} r_{\alpha_{k}}=\left(1-\alpha_{i}\right) Q_{i}^{\prime} r_{\bar{e}}\left[q_{k}+\left(1-\alpha_{k}\right) r Q_{k}^{\prime}\right] \\
& =q_{i \bar{e}} q_{k}+\left(1-\alpha_{i}\right) Q_{i}^{\prime}\left(1-\alpha_{k}\right) Q_{k}^{\prime} r r_{\bar{e}}
\end{aligned}
$$

for all $i \neq k$, and

$$
q_{k k}=-r Q_{k}^{\prime}+\left(1-\alpha_{k}\right) Q_{k}^{\prime} r_{\alpha_{k}}=-r Q_{k}^{\prime}+q_{k \bar{e}} q_{k}+\left[\left(1-\alpha_{k}\right) Q_{k}^{\prime}\right]^{2} r r_{\bar{e}}
$$

\section{Choice of the cap}

The effect of $\bar{e}$ on welfare for any given state of demand and supply is

$$
\begin{aligned}
\frac{\partial W}{\partial \bar{e}} & =\sum_{i}\left(1-\alpha_{i}\right) r q_{i \bar{e}}-D^{\prime} \sum_{i} q_{i \bar{e}}=\left(r-D^{\prime}\right) \sum_{i} q_{i \bar{e}}-r \sum_{i} \alpha_{i} q_{i \bar{e}} \\
& =\left(r-D^{\prime}\right)-D^{\prime} \sum_{i} \alpha_{i} q_{i \bar{e}}=\left(r-D^{\prime}\right)-D^{\prime} \sum_{i} \alpha_{i}\left(1-\alpha_{i}\right) Q_{i}^{\prime} r_{\bar{e}}
\end{aligned}
$$

that $\operatorname{sing} Q_{i}^{\prime}=1 /\left(P_{i}^{\prime}-C_{i}^{\prime \prime}\right)$ yields equation $(22)$.

Choice of the OBA rates $\alpha_{i}$

Since $\sum q_{i}=\bar{e}+\sum \alpha_{i} q_{i}$, we have $\sum q_{i k}=q_{k}+\sum \alpha_{i} q_{i k}$, so that

$$
\frac{\partial W}{\partial \alpha_{k}}=\left(r-D^{\prime}\right) \sum_{i} q_{i k}-r \sum_{i} \alpha_{i} q_{i k}=\left(r-D^{\prime}\right) q_{k}-D^{\prime} \sum_{i} \alpha_{i} q_{i k}
$$

We now use the Preliminary results above to isolate the effect of releasing $q_{k}$ free permits from the "subsidy effect". Using equations (49) and (50) yields

$$
\begin{aligned}
\frac{\partial W}{\partial \alpha_{k}}=[ & \left.\left(r-D^{\prime}\right)-D^{\prime} \sum_{i} \alpha_{i} q_{i \bar{e}}\right] q_{k} \\
& \quad-D^{\prime}\left\{\left(1-\alpha_{k}\right) Q_{k}^{\prime} \sum_{i}\left[\alpha_{i}\left(1-\alpha_{i}\right) Q_{i}^{\prime}\right] r r_{\bar{e}}-\alpha_{k} r Q_{k}^{\prime}\right\}
\end{aligned}
$$

Since the first bracketed term is equal to the derivative of welfare with respect to $\bar{e}$ times output $q_{k}$, making use of (48) we obtain

$$
\begin{aligned}
\frac{\partial W}{\partial \alpha_{k}} & =\frac{\partial W}{\partial \bar{e}} q_{k}-\operatorname{rr}_{\bar{e}} Q_{k}^{\prime} D^{\prime} \sum_{i}\left[\alpha_{i}\left(1-\alpha_{i}\right)\left(1-\alpha_{k}\right) Q_{i}^{\prime}-\alpha_{k}\left(1-\alpha_{i}\right)^{2} Q_{i}^{\prime}\right] \\
& =\frac{\partial W}{\partial \bar{e}} q_{k}-r r_{\bar{e}} Q_{k}^{\prime} D^{\prime} \sum_{i}\left[\left(1-\alpha_{i}\right)\left(\alpha_{i}-\alpha_{k}\right) Q_{i}^{\prime}\right]
\end{aligned}
$$


Taking expectations and using the fact that $\bar{e}$ is optimal chosen we obtain

$$
\mathbb{E}\left[\frac{\partial W}{\partial \bar{e}} q_{k}\right]=\mathbb{E}\left[\frac{\partial W}{\partial \bar{e}}\right] \mathbb{E}\left[q_{k}\right]+\operatorname{cov}\left(\frac{\partial W}{\partial \bar{e}}, q_{k}\right)=\operatorname{cov}\left(\frac{\partial W}{\partial \bar{e}}, q_{k}\right)
$$

But $Q_{i}^{\prime}=-1 /\left(C_{i}^{\prime \prime}-p_{i}^{\prime}\right)$, which shows that expression 23 holds.

\section{B.2 Linear specification and proof of Proposition 4}

\section{Permit market equilibrium}

Let $\beta_{i}=b_{i}+\gamma_{i}$ be the slope of the sectorial demand, $Q_{i}(t)=\left(a_{i}+\theta_{i}-t\right) / \beta_{i}$. We write $\tilde{a}_{i}=a_{i}+\theta_{i}$, the intersect of the demand in state $\theta_{i}$. At equilibrium $q_{i}=\left(\tilde{a}-\left(1-\alpha_{i}\right) r\right) / \beta_{i}$ and the permit price clears the permit market $\sum_{i} q_{i}=\bar{e}+\sum_{i} \alpha_{i} q_{i}$, that is,

$$
\bar{e}=\sum_{i}\left[\left(1-\alpha_{i}\right) \frac{\tilde{a}_{i}}{\beta_{i}}\right]-r \sum_{i}\left[\frac{\left(1-\alpha_{i}\right)^{2}}{\beta_{i}}\right]
$$

so the permit price is

$$
r=\frac{\sum_{i}\left[\left(1-\alpha_{i}\right) \tilde{a}_{i} / \beta_{i}\right]-\bar{e}}{\sum_{i}\left[\left(1-\alpha_{i}\right)^{2} / \beta_{i}\right]}
$$

\section{Choice of the cap}

From (51) and (54) we obtain that the effect of $\bar{e}$ on welfare is given by

$$
\frac{\partial W}{\partial \bar{e}}=(r-h)-h \sum_{i} \alpha_{i} q_{i \bar{e}}=r-h-h \frac{\sum_{i}\left[\alpha_{i}\left(1-\alpha_{i}\right) / \beta_{i}\right]}{\sum_{i}\left(1-\alpha_{i}\right)^{2} / \beta_{i}}
$$

so at the optimal $\bar{e}\left(\alpha_{1}, \ldots, \alpha_{n}\right)$ we have

$$
\mathbb{E} r=\frac{\sum_{i}\left(1-\alpha_{i}\right) / \beta_{i}}{\sum_{i}\left(1-\alpha_{i}\right)^{2} / \beta_{i}} h
$$

and, from (54), the optimal cap is

$$
\bar{e}\left(\alpha_{1}, . ., \alpha_{n}\right)=\sum_{i}\left(1-\alpha_{i}\right)\left(a_{i}-h\right) / \beta_{i}
$$

\section{Choice of the OBA rates $\alpha_{k}$}

The optimal $\alpha_{k}$ satisfies equation (23). Using $D^{\prime}=h, Q_{i}^{\prime}=-1 / \beta_{i}$ and $r_{\bar{e}}=1 / \sum((1-$ $\left.\alpha_{i}\right)^{2} / \beta_{i}$ ) yields the first order condition:

$$
\begin{aligned}
\operatorname{cov}\left(\frac{\partial W}{\partial \bar{e}}, q_{k}\right) & =\frac{h \mathbb{E}[r]}{\beta_{k} \sum_{i}\left[\left(1-\alpha_{i}^{2}\right) / \beta_{i}\right]} \sum_{i}\left[\frac{1-\alpha_{i}}{\beta_{i}}\left(\alpha_{k}-\alpha_{i}\right)\right] \\
& =\frac{h^{2}}{\beta_{k}} \frac{\sum_{i}\left(1-\alpha_{i}\right) / \beta_{i}}{\left[\sum_{i}\left(1-\alpha_{i}\right)^{2} / \beta_{i}\right]^{2}} \sum_{i}\left[\frac{1-\alpha_{i}}{\beta_{i}}\left(\alpha_{k}-\alpha_{i}\right)\right] \text { using eq. (55) }
\end{aligned}
$$


We also know that

$$
\begin{aligned}
\operatorname{cov}\left(\frac{\partial W}{\partial \bar{e}}, q_{k}\right) & =\operatorname{cov}\left(r, q_{k}\right)=\operatorname{cov}\left(r,\left(\theta_{k}-\left(1-\alpha_{k}\right) r\right) / \beta_{k}\right) \\
& =\frac{\left(1-\alpha_{k}\right) / \beta_{k}}{\left(\sum_{i}\left(1-\alpha_{i}\right)^{2} / \beta_{i}\right)^{2}} \sum_{i}\left[\frac{\left(1-\alpha_{i}\right)^{2}}{\beta_{i}}\left(\frac{\sigma_{k}^{2}}{\beta_{k}}-\frac{\sigma_{i}^{2}}{\beta_{i}}\right)\right]
\end{aligned}
$$

so, combining the two expressions above, the optimal rate $\alpha_{k}$ satisfies

$$
\sum_{i}\left[\frac{\left(1-\alpha_{i}\right)^{2}}{\beta_{i}}\left(\frac{\sigma_{k}^{2}}{\beta_{k}}-\frac{\sigma_{i}^{2}}{\beta_{i}}\right)\right]=h^{2}\left[\sum_{i} \frac{1-\alpha_{i}}{\beta_{i}}\right] \sum_{i}\left[\frac{1-\alpha_{i}}{\beta_{i}} \frac{\alpha_{k}-\alpha_{i}}{1-\alpha_{k}}\right]
$$

Using the latter to substract expressions associated to $k$ and $l$, and writing $\left(\alpha_{k}-\alpha_{i}\right) /(1-$ $\left.\alpha_{k}\right)=\left(1-\alpha_{i}\right) /\left(1-\alpha_{k}\right)-1$, yields

$$
\frac{\sigma_{k}^{2}}{\beta_{k}}-\frac{\sigma_{l}^{2}}{\beta_{l}}=h^{2}\left[\sum_{i} \frac{1-\alpha_{i}}{\beta_{i}}\right]\left[\frac{1}{1-\alpha_{k}}-\frac{1}{1-\alpha_{l}}\right]
$$

Therefore, if $\sigma_{k}^{2} / \beta_{k}>\sigma_{l}^{2} / \beta_{l}$ then $\alpha_{k}>\alpha_{l}$.

Since $\alpha_{1}$ is the lowest rate, we can set $\alpha_{1}=0$ and using equation we we obtain for all other $k=2, \ldots, n$

$$
\alpha_{k}=\frac{\Delta_{k}}{\Delta_{k}+\Psi}
$$

where $\Delta_{k}$ is given by 26 and $\Psi=\sum_{i}\left(1-\alpha_{i}\right) / \beta_{i}$. Finally, summing over $k$ gives that $\Psi$ is a solution of the equation

$$
\sum_{i=1}^{n} \frac{1}{\beta_{i}\left(\Delta_{i}+x\right)}=1
$$

There is a unique solution to this equation between 0 and $+\infty$, it is lower than $\sum_{i}\left(1 / \beta_{i}\right)$, because the left-hand-side is strictly decreasing, and, since $\Delta_{1}=0$, it is equal to $+\infty$ for $x=0$, and for $x=\sum_{i} 1 / \beta_{i}$, it is lower than 1 .

Then for $\Psi$ the unique positive solution of this equation, define $\alpha_{i}=\Delta_{i} /\left(\Delta_{i}+\Psi\right)$ for all $i>1$ which is between 0 and 1 , and $\bar{e}$ is given by equation (56). They all satisfy the first order conditions and thus, maximize expected welfare.

\section{B.3 Proof of Proposition 5}

Let us assume that (i) $a>h(1+2 \gamma / b)$ and (ii) $\sigma_{1}^{2}<h^{2} \sum_{i=1}^{n}\left(1-\alpha_{i}\right)$ hold, and show that the optimal OBA scheme in Proposition 4 can be implemented with a menu of OBA rates and lump-sum allocations $\left\{\left(\alpha_{j}, \hat{e}_{j}\right) / i=1, \ldots, n\right\}$ as described in (33).

At the optimum scheme described in Proposition 4, for $\beta_{i}=\beta \forall i$, we have $\psi=\sum_{i}(1-$ $\left.\alpha_{i}\right) / \beta$ and $\alpha_{i}=\Delta_{i} /\left(\delta_{i}+\psi\right)$ and $\sigma_{i}^{2}-\sigma_{1}^{2}=\alpha_{i} \beta \psi h^{2}$

We proceed in three steps: we first show that the derivative of firm $i+1$ 's profit with respect to $\alpha$ is higher than the derivative of firm $i$ 's. Then we show that this result ensures that the lump-sum (free) allocations (33) are sufficient for the self-selection constraints to 
hold. And finally we show that the regulator has enough permits to offer the lump-sum allocations (33).

We first show that the influence of the OBA rate on profit is larger for the more volatile sectors

$$
\mathbb{E}\left[\frac{\partial \pi_{i+1}\left(\theta_{i+1}, r, \alpha\right)}{\partial \alpha}\right] \geq \mathbb{E}\left[\frac{\partial \pi_{i}\left(\theta_{i}, r, \alpha\right)}{\partial \alpha}\right]
$$

Using (29) and (31), the above inequality can be written as

$$
\left(1-\alpha_{i+1}\right) \sigma_{i+1}^{2} \geq\left(1-\alpha_{i}\right) \sigma_{i}^{2}
$$

for $i=1 . . n-1$. Then, using $\sigma_{i}^{2}-\sigma_{1}^{2}=h^{2} \beta \alpha_{i} \psi /\left(1-\alpha_{i}\right)$, eq. 62 is equivalent to

$$
\begin{aligned}
\left(1-\alpha_{i+1}\right)\left(\sigma_{i+1}^{2}-\sigma_{1}^{2}\right)+\left(1-\alpha_{i+1}\right) \sigma_{1}^{2} & \geq\left(1-\alpha_{i}^{2}\right)\left(\sigma_{i}^{2}-\sigma_{1}^{2}\right)+\left(1-\alpha_{i}\right) \sigma_{1}^{2} \\
\left(\alpha_{i+1}-\alpha_{i}\right) \beta \psi h^{2} & \geq\left(\alpha_{i+1}-\alpha_{i}\right) \sigma_{1}^{2} \\
h^{2} \sum_{i}\left(1-\alpha_{i}\right) & \geq \sigma_{1}^{2}
\end{aligned}
$$

which corresponds to assumption (ii) in Proposition 5.

Thanks to this property, all differences $\hat{e}_{i+1}-\hat{e}_{i}$ in (33) are positive, and the self-selection constraints (28) are all satisfied. Consider $i, j=1, \ldots, n$, sector $i$ prefers its option to option $j$ if $i<j$ :

$$
\begin{aligned}
& \mathbb{E}\left[\pi_{i}\left(\theta_{i}, r, \alpha_{j}\right)-\pi_{i}\left(\theta_{i}, r, \alpha_{i}\right)\right]=\sum_{k=i}^{j-1} \mathbb{E}\left[\pi_{i}\left(\theta_{i}, r, \alpha_{k+1}\right)-\pi_{i}\left(\theta_{i}, r, \alpha_{k}\right)\right] \\
& \leq \sum_{k=i}^{j-1} \mathbb{E}\left[\pi_{k}\left(\theta_{i}, r, \alpha_{k+1}\right)-\pi_{k}\left(\theta_{i}, r, \alpha_{k}\right)\right] \text { thanks to } 61 \\
& \leq \sum_{k=i}^{j-1} \mathbb{E}[r]\left(\hat{e}_{k}-\hat{e}_{k+1}\right)=\mathbb{E}[r]\left(\hat{e}_{i}-\hat{e}_{j}\right) \text { by definition of the menu }
\end{aligned}
$$

A similar reasoning shows that it also holds for $i>j$.

We now establish that thanks to assumption (i) the budget-balance constraint is satisfied. The regulator has enough permits to implement the optimal scheme with the allocations described in 33

$$
\bar{e} \geq \sum_{i=1}^{n} \hat{e}_{i}=\sum_{i=1}^{n-1} i \times \frac{1}{\mathbb{E}[r]} \mathbb{E}\left[\pi_{i}\left(\theta_{i}, r, \alpha_{i+1}\right)-\pi_{i}\left(\theta_{i}, r, \alpha_{i}\right)\right]
$$

The difference in profit is equal to

$$
\begin{aligned}
& \mathbb{E}\left[\pi_{i}\left(\theta_{i}, r, \alpha_{i+1}\right)-\pi_{i}\left(\theta_{i}, r, \alpha_{i}\right)\right]=\frac{\gamma}{2 \beta^{2}}\left(\alpha_{i+1}-\alpha_{i}\right) \mathbb{E}\left[r\left[2\left(a+\theta_{i}\right)-\left(2-\alpha_{i+1}-\alpha_{i}\right) r\right]\right] \\
& =\frac{\gamma}{2 \beta^{2}}\left(\alpha_{i+1}-\alpha_{i}\right)\left\{\mathbb{E}[r] \times\left[2 a-\left(2-\alpha_{i+1}-\alpha_{i}\right) \mathbb{E}[r]\right]+\operatorname{cov}\left(2 \theta_{i}-\left(2-\alpha_{i+1}-\alpha_{i}\right) r, r\right)\right\}
\end{aligned}
$$


So the constraint $(63)$ is equivalent to

$$
\bar{e}>\frac{\gamma}{\beta^{2}} \sum_{i=1}^{n-1} i\left(\alpha_{i+1}-\alpha_{i}\right)\left\{\left[a-\left(1-\frac{\alpha_{i+1}+\alpha_{i}}{2}\right) \mathbb{E}[r]\right]+\operatorname{cov}\left(\theta_{i}-\left(1-\frac{\alpha_{i+1}+\alpha_{i}}{2}\right) r, \frac{r}{\mathbb{E}[r]}\right)\right\}
$$

Let us now establish an upper bound for the two terms on the right-hand side. Since $\alpha_{n}<1$ we have that

$$
\frac{\gamma}{\beta^{2}} \sum_{i=1}^{n-1} i\left(\alpha_{i+1}-\alpha_{i}\right) a=\frac{\gamma}{\beta^{2}} \sum_{i=1}^{n-1}\left(\alpha_{n}-\alpha_{i}\right) a<\psi \frac{\gamma}{\beta} a
$$

and

$\sum_{j}\left(1-\alpha_{j}\right)^{2} \times \operatorname{var}(r)=\frac{\sum_{j}\left(1-\alpha_{j}\right)^{2} \sigma_{j}^{2}}{\sum_{j}\left(1-\alpha_{j}\right)^{2}}=\frac{\sum_{j}\left(1-\alpha_{j}\right)^{2}\left(\sigma_{j}^{2}-\sigma_{1}^{2}\right)}{\sum_{j}\left(1-\alpha_{j}\right)^{2}}+\sigma_{1}^{2}=\frac{\sum_{j}\left(1-\alpha_{j}\right) \alpha_{j}}{\sum_{j}\left(1-\alpha_{j}\right)^{2}} \beta \psi h^{2}+\sigma_{1}^{2}$

so that the covariance term is lower than $h$

$$
\begin{aligned}
& \operatorname{cov}\left(\theta_{i}-\left(1-\frac{\alpha_{i+1}+\alpha_{i}}{2}\right) r, \frac{r}{\mathbb{E} r}\right)= \\
& \frac{1}{\mathbb{E} r \sum_{j}\left(1-\alpha_{j}\right)^{2}}\left\{\left(1-\alpha_{i}\right)\left(\sigma_{i}^{2}-\sigma_{1}^{2}\right)+\frac{\alpha_{i+1}-\alpha_{i}}{2} \sigma_{1}^{2}-\left(1-\frac{\alpha_{i+1}+\alpha_{i}}{2}\right) \frac{\sum_{j}\left(1-\alpha_{j}\right) \alpha_{j}}{\sum_{j}\left(1-\alpha_{j}\right)^{2}} \beta \psi h^{2}\right\} \\
&<\frac{1}{\beta \psi h}\left\{\alpha_{i} \beta \psi h^{2}+\frac{\alpha_{i+1}-\alpha_{i}}{2} \sigma_{1}^{2}\right\}=\frac{1}{\beta \psi h}\left\{\alpha_{i}\left(\beta \psi h^{2}-\frac{\sigma_{1}^{2}}{2}\right)+\frac{\alpha_{i+1}}{2} \sigma_{1}^{2}\right\} \\
&<\frac{1}{\beta \psi h} \beta \psi h^{2}=h
\end{aligned}
$$

where the last inequality is obtained using $h^{2}>\sigma_{1}^{2}$ (from (ii)), $\beta \psi>1$, and $\alpha_{i}<\alpha_{i+1}<1$. Then, the right-hand side of $(63)$ is lower than

$$
\frac{\gamma}{\beta^{2}} \beta \psi a+\frac{\gamma}{\beta^{2}} \sum_{i=1}^{n-1}\left[i\left(\alpha_{i+1}-\alpha_{i}\right)\right] h<\frac{\gamma}{\beta^{2}} \beta \psi a+\frac{\gamma}{\beta^{2}} \beta \psi h=(a+h) \frac{\gamma}{\beta} \psi
$$

and

$$
a>h(1+2 \gamma / b) \Leftrightarrow(a+h) \frac{\gamma}{\beta}<a-h
$$

so that, if $a>h(1+2 \gamma / b)$ then (63) is satisfied, because $\bar{e}>a-h$ at the optimal scheme.

\section{B.4 Proof of Corollary 1}

Let us consider the slightly more general situation, the one in Proposition $4: p_{i}=a_{i}+\theta_{i}-b_{i} q_{i}$ and $C_{i}=\gamma_{i} q_{i}^{2} / 2$ denoting $\beta_{i}=b_{i}+\gamma_{i}$ and $\tilde{a}_{i}=a_{i}+\theta_{i}$. Using the results in this Proposition and setting $\alpha_{1}=0$, the optimal cap is given by

$$
\bar{e}=\left(a_{1}-h\right) / \beta_{1}+\left(1-\alpha_{2}\right)\left(a_{2}-h\right) / \beta_{2}
$$


and the expression in Corollary 1 is obtained by simply replacing $a_{1}=a_{2}=a$ and $\beta_{1}=\beta_{2}=$ 2. Let us write $\Delta_{2}=\left[\sigma_{2}^{2} / \beta_{2}-\sigma_{1}^{2} / \beta_{1}\right] / h^{2}$ as in Proposition 4. The optimal $\alpha_{2}$ is equal to $\Delta_{2} /\left(\Delta_{2}+\Psi\right)$ with $\Psi=1 / \beta_{1}+\left(1-\alpha_{2}\right) / \beta_{2}$, so $\left(1-\alpha_{2}\right)\left(\Delta_{2}+\Psi\right)=\Psi$

$$
\left(1-\alpha_{2}\right)\left(\Delta_{2}+1 / \beta_{1}+\left(1-\alpha_{2}\right) / \beta_{2}\right)=1 / \beta_{1}+\left(1-\alpha_{2}\right) / \beta_{2}
$$

This implies that $\left(1-\alpha_{2}\right) / \beta_{2}$ is the positive solution of the equation

$$
x^{2}+x \Delta-\frac{1}{\beta_{1} \beta_{2}}=0
$$

with $\Delta=\Delta_{2}+1 / \beta_{1}-1 / \beta_{2}$ (which corresponds to the value of $\Delta$ defined in Corollary 1 for $\beta_{1}=\beta_{2}=2$ ), which yields

$$
\frac{1-\alpha_{2}}{\beta_{2}}=\frac{1}{2}\left[\left(\Delta^{2}+\frac{4}{\beta_{1} \beta_{2}}\right)^{1 / 2}-\Delta\right] .
$$

The equivalent expression in Corollary 1 is obtained, again, by simply replacing $\beta_{1}=\beta_{2}=2$ and $\sigma_{1}=0$, and making use of Lemma 3 on the equivalence of schemes.

\section{B.5 Proof of Corollary 2}

We will work with a slightly more general quadratic framework than what the proof of the corollary requires, which assumes values of $b_{1}=\gamma_{1}=b_{2}=\gamma_{2 d}=1$. To obtain the optimal OBA rate given a leakage rate $l$, we rewrite the welfare function in two steps so that, redefining parameters accordingly, we can use the above generalization of Corollary 1.

In equilibrium the foreign marginal cost is equal to the output price so that $q_{2 f}\left(q_{2 d}, \theta_{2}\right)=$ $\left(a_{2}+\theta_{2}-b_{2} q_{2 d}\right) /\left(b_{2}+\gamma_{2 f}\right)$, and the leakage rate is $l=-\partial q_{2 f} / \partial q_{2 d}=b_{2} /\left(b_{2}+\gamma_{2 f}\right)$. Using this, the sectorial surplus net of foreign costs can be written as a function of $q_{2 d}$ only as follows

$$
S_{2 d}\left(q_{2 d} ; \theta_{2}\right)=S_{2}\left(q_{2 d}+q_{2 f}\left(q_{2 d}, \theta_{2}\right) ; \theta_{2}\right)-C_{2 f}\left(q_{2 f}\left(q_{2 d}, \theta_{2}\right)\right)
$$

which is a quadratic function of $q_{2 d}$. And by an envelope argument, its derivative with respect to $q_{2 d}$ is $\left(a_{2}+\theta_{2}\right)(1-l)-b_{2}(1-l) q_{2 d}$.

Consequently, maximizing expected welfare in 36 is equivalent to maximizing (we can omit the constant term $h q_{2 f}\left(0, \theta_{2}\right)$ from the maximization)

$$
W=\mathbb{E}\left\{\left[S_{1}\left(q_{1}\right)-C_{1}\left(q_{1}\right)+S_{2 d}\left(q_{2 d} ; \theta_{2}\right)-C_{2 d}\left(q_{2 d}\right)\right]-h\left[q_{1}+(1-l) q_{2 d}\right]\right\}
$$

A change of variable is now sufficient to get the result. Define $x_{2}=(1-l) q_{2 d}$ and rewrite everything as a function of $x_{2}$. Letting $\tilde{b}_{2}=b_{2} /(1-l)$ and $\tilde{\gamma}_{2}=\gamma_{2 d} /(1-l)^{2}$ we have

$$
\tilde{S}_{2}\left(x_{2}, \theta_{2}\right)=S_{2 d}\left(\frac{x_{2}}{1-l}, \theta_{2}\right)-S_{2 d}\left(0, \theta_{2}\right)=\left(a_{2}+\theta_{2}-\tilde{b}_{2} x_{2} / 2\right) x_{2}, \text { and } \tilde{C}_{2}\left(x_{2}\right)=\frac{\tilde{\gamma}_{2}}{2} x_{2}^{2}
$$

so welfare as a function of $x_{2}$ becomes (omitting the constant $S_{2 d}\left(0, \theta_{2 d}\right)$ )

$$
W=S_{1}\left(q_{1}\right)-C_{1}\left(q_{1}\right)+\tilde{S}_{2}\left(x_{2}, \theta_{2}\right)-\tilde{C}_{2}\left(x_{2}\right)-h\left(q_{1}+x_{2}\right)
$$


where

$$
q_{1}+x_{2}=q_{1}+(1-l) q_{2 d}=\bar{e}+\left(\alpha_{2}-l\right) q_{2 d}=\bar{e}+\tilde{\alpha}_{2} x_{2} .
$$

comes from the fact that the renormalized OBA rate is $\tilde{\alpha}_{2}=\left(\alpha_{2}-l\right) /(1-l)$.

Then, use the above result (in the general version of Corollary 1) to get that the optimal renormalized OBA rate satisfies the equation

$$
\frac{1-\tilde{\alpha}_{2}}{\tilde{\beta}_{2}}=\frac{1}{2}\left[\left(\Delta_{l}^{2}+\frac{4}{\beta_{1} \tilde{\beta}_{2}}\right)^{1 / 2}-\Delta_{l}\right]
$$

in which $\Delta_{l}$ correspond to the $\Delta$ above with the renormalized parameters $\left(\tilde{\beta}_{2}=(2-l) /(1-l)^{2}\right.$ for $b_{2}=\gamma_{2}=1$ )

$$
\Delta_{l}=\frac{1}{h^{2}} \frac{\sigma_{2}^{2}}{\tilde{\beta}_{2}}+\frac{1}{\beta_{1}}-\frac{1}{\tilde{\beta}_{2}}=\frac{\sigma_{2}}{h^{2}} \frac{(1-l)^{2}}{2-l}+\frac{1}{2}-\frac{(1-l)^{2}}{2-l}
$$

which corresponds to equation 38 . Finally, replace $\tilde{\beta}_{2}$ by $(2-l) /(1-l)^{2}$ and $\beta_{1}$ by 2 to get (37) as in Corollary 2. 